\title{
La evolución de la problemática urbana en el marco de la teoría social
}

\author{
José Miguel Santos Preciado
}

\section{INTRODUCCIÓN}

Si intentamos juzgar a la geografía urbana por los frutos obtenidos en este campo concreto del saber geográfico, podemos adelantar que «hay muy poco escrito antes de 1950 , y, además, la producción científica realizada hasta entonces, ha tenido muy poco impacto en la elaboración posterior" (Herbert y Thomas, 1982: 1). La situación se transformaría de forma espectacular a partir de los años sesenta, cuando los nuevos paradigmas científicos provenientes de la sociología y de la economía, fundamentalmente, influenciarian de forma decisiva la orientación investigadora de nuestra disciplina. Esta posición de desventaja relativa, provocada por el aislamiento, se agravó aún más al haberse realizado las principales contribuciones al estudio de la ciudad desde otras ramas ajenas a la geografía.

Debido a la trascendencia que estos análisis previos han tenido en el desarrollo de la geografía urbana, resulta de gran interés profundizar en las raíces del pensamiento social, que han permitido cristalizar los diferentes enfoques epistemológicos y metodológicos, de los que hoy es, sin duda, usufructuaria esta importante rama geográfica. 


\section{LOS GRANDES PARADIGMAS DE LA TEORIA SOCIAL}

El elevado grado de pluralismo que hoy existe en las ciencias sociales permite disponer de variadas referencias teóricas para el análisis del urbanismo desde una perspectiva social. Sin embargo, «el indefinido repertorio de sociologias particulares existentes, cada una de ellas desmembrada en varias corrientes metodológicas, remite a cuatro grandes paradigmas, cuya exposición resulta suficiente para desenvolverse en ciencias sociales $y$, desde luego, en el ámbito de los métodos. Estos paradigmas son el durkheimniano, el neopositivista, el weberiano y el marxista" (Martín Serrano, 1978: 10). Dejaremos de lado, el paradigma neopositivista, más entroncado con las corrientes neoclásicas de la ciencia económica, para centrarnos en los otros tres.

Tanto Marx, como Weber y Durkheim desarrollaron sus teorias a partir de la transformación que el capitalismo venía experimentando en el mundo occidental, uno de cuyos rasgos más transcendentales era el enorme crecimiento de la ciudad. A pesar de ello, como veremos, lo urbano no fue considerado, en cuanto tal, como un fin fundamental de sus preocupaciones teóricas, sino más bien, como la consecuencia o efecto del funcionamiento global de la sociedad. Sin embargo, la importancia alcanzada por sus concepciones teóricas y metodológicas y su influencia en las principales disciplinas, que desde comienzo del siglo $x x$ trataban de interpretar el fenómeno urbano, nos obliga a detenernos $y$ analizarlas con un cierto detalle.

\section{Los fundamentos básicos de la epistemologia marxista, una teoría social, primitivamente al margen de lo urbano}

Dos son los principios básicos sobre los que se apoya el análisis marxista de la realidad social. El primero, aunque no pueda ser considerado como exclusivo del marxismo, hace referencia al carácter holista del conocimiento de lo social. Ningún aspecto de la realidad puede ser analizado de forma parcial, sin una referencia a la totalidad de la cual procede. Esta forma de relacionar lo particular en lo general debe, según el método marxista, ser integrada en la concepción dialéctica, originaria de Hegel, y que Marx transplantó del campo de las ideas al de los hechos. El método dialéctico remite a una lógica del mismo tipo, donde encuentra su fundamento la construcción de la ciencia social. "La dialéctica pro- 
pone un proceso de comprensión que permite la interpretación de los contrarios, incorpora contradicciones y paradojas y apunta a los procesos de resolución" (Harvey, 1976: 15). Se rompe, así, con la primitiva idea del evolucionismo lineal, entonces imperante, que presuponía que ni en la naturaleza ni en la historia acontecen cambios repentinos y de que todo cambio acaecido en el mundo se realiza gradualmente. Esta forma de razonar dialéctica se concibe "como la más adecuada a la práxis, cuando la realidad material puede ser modificada por la actividad del sujeto pensante" (Martín Serrano, 1978: 71). Si la realidad es contradictoria y puede ser superada hacia un nuevo estadio cualitativamente diferente, el sujeto puede actuar, contribuyendo a su transformación.

El segundo principio básico consiste en afirmar que la conciencia humana que procede de la realidad es la mayoría de las veces falsa $-y$ por lo tanto ideológica-. "De ello se deduce que la realidad esencial que la ciencia intenta descubrir puede resultar oscurecida por las formas externas, tal como la realidad se nos presenta en nuestra diaria experiencia. Por lo tanto, para Marx, la tarea de la ciencia es penetrar en las relaciones esenciales por encima de las apariencias (Saunders, 1981: 15).

Este intento de construir la ciencia verdadera lleva consigo la utilización de las categorías adecuadas para el análisis social. El problema se presenta al comprobar que "la ciencia social formula conceptos, categorías relaciones y métodos, que no son independientes de las relaciones sociales que existen en la sociedad, por lo que no pueden ser formuladas en abstracto" (Harvey, 1976: 11). La forma de superar el peligro de no caer en la ideología es tener presente que las categorías verdaderamente científicas tienen un origen histórico y deben ser deducidas directamente de la praxis. Se establece así un nexo de unión extrecho entre teoría y práxis que concibe la realidad en una dirección determinada con objeto de transformarla.

A partir de estas dos referencias: concepto holista de la realidad social desde una perspectiva dialéctica y carácter ideológico de la mayoria de las construcciones teóricas existentes, se pivota todo el edificio epistemológico marxista. Su aplicación al conocimiento de la historia ha dado lugar al materialismo histórico, concebido como una verdadera ciencia teórica y abstracta.

La historia se convierte, de esta manera, en la historia de los modos de producción. El concepto de modo de producción representa el armazón básico del materialismo histórico. Es, pues, un concepto abstracto que estructura los diferentes campos de la realidad social en torno a tres 
instancias: la económica, la jurídico-política y la ideológica. La primera representa la infraestructura de la sociedad, mientras que las dos últimas integran la superestructura. La diferencia existente entre un concepto teórico como éste, cristalizado por interpretación de la realidad, y los resultados de un análisis concreto en un contexto determinado, se salva con la creación de un nuevo concepto: la formación social. La formación social representa una realidad histórica determinada en cuya base económica coexisten varios modos de producción.

En la Contribución a la Crítica de la Economía Política, Marx introduce dos nuevos conceptos como integrantes de un modo de producción determinado: las fuerzas productivas y las relaciones de producción, y a partir de ellos y de sus contradicciones nos señala el camino para comprender el cambio social. Las fuerzas productivas representan una combinación determinada de los medios de producción y la fuerza de trabajo en un proceso de trabajo. La visión marxista del desarrollo de la historia introduce momentos de ruptura, caracterizados por las dificultades de las fuerzas productivas para reproducir el sistema social de un modo de producción dominante, debido a las contradicciones de las relaciones de producción. Estas relaciones de producción, que se manifiestan en las tres instancias: económica, política e ideológica, serían, según señalan Marx y Engels en el Manifiesto Comunista, relaciones de explotación en un contexto de lucha de clases. El descubrimiento de este nuevo carácter de las relaciones humanas constituye uno de los elementos básicos del planteamiento teórico marxista.

Si bien Marx expuso, de manera general, las condiciones de funcionamiento de la sociedad, no tuvo tiempo de profundizar más que en la instancia económica del modo de producción capitalista, por lo que «de forma razonable podemos ver El Capital como un verdadero paradigma de la investigación científica" (Saunders, 1981: 18) desde el punto de vista marxista. La importancia de El Capital es básica para comprender los logros y a la vez la debilidad de su entramado teórico. El método marxista difiere sustancialmente de la corriente científica neopositivista. Por ello, no utiliza, como el método deductivo, leyes de partida, desde las que deducir las relaciones sociales esenciales, ni tan siquiera mantiene una apoyatura directa respecto a los hechos empíricos. Únicamente, el descubrimiento de unas categorías capaces de poner de manifiesto la organización social de dominación permite la comprensión de la realidad social y su transformación. La debilidad del método se deriva de la ausencia de garantías de objetividad por encima de los propios agentes sociales. 
Nos vamos a detener a continuación en la exposición del intento del propio Marx en El Capital por descubrir las claves del modo de producción capitalista (MPC) en la esfera económica. El interés es doble: por una parte, por constituir la obra clave del pensamiento marxista, y por otra, por la repercusión que ha tenido en los diversos autores marxistas que se han ocupado del estudio de la ciudad, alguno de los cuales, como D. Harvey, han utilizado en su obra las mismas categorias deducidas por Marx.

El método de K. Marx en El Capital consistió según P. Sweezy en poner al desnudo la ley económica del movimiento de la sociedad moderna. Pero El Capital, que puede dar la impresión de una obra fundamentalmente económica, encerraria dentro de si, las relaciones de clase que subyacen en la sociedad capitalista, a la vez que los mecanismos que explican el primitivo despegue de las fuerzas productivas y las contradicciones inherentes al sistema capitalista. Marx introduce, pues, categorias económicas que expresan relaciones sociales encubiertas, categorías no absolutas sino históricas.

Toda la estructura de El Capital se manifiesta en la relación directa que se produce entre el capital y el trabajo. El resto de las relaciones sociales son introducidas posteriormente. Para ello, era, pues, necesario que se produjeran las condiciones históricas pertinentes para que se liberaran ambos de las trabas impuestas por los anteriores modos de producción. «Por lo tanto, el proceso que engendra al capitalismo solo puede ser uno: el proceso de disociación entre el obrero y la propiedad sobre las condiciones de su trabajo, proceso que de una parte convierte en capital los medios sociales de vida y de producción, mientras que de otra parte convierte a los productores directos en obreros asalariados (Marx, 1978: 608).

Este proceso histórico no se produjo de forma igual en todos los países, pero aún con modalidades diferentes, se llegó al mismo resultado: la ruptura de todos los lazos feudales que ataban al hombre a la tierra, su transformación en mercancía en el nuevo orden económico y la progresiva concentración de los medios de producción en manos de los capitalistas. De esta forma, el nuevo obrero asalariado fue obligado por la fuerza a convertirse en mercancía en el nuevo proceso de producción capitalista, a la vez que debería obtener en el mercado las mercancías necesarias para su subsistencia.

Después de analizar históricamente el momento de ruptura con el modo de producción anterior, Marx se introduce de lleno en el estudio de las categorias básicas propias del MPC. ¿Cuál es el hecho esencial que 
diferenciaría este modo de producción de los anteriores? Según los economistas clásicos, el gran desarrollo experimentado por las fuerzas productivas, que ha dado lugar a la sociedad moderna, estaria ligado al progresivo incremento sufrido por la división del trabajo. La especialización y el intercambio ventajoso para todos los productores serían los factores claves que explicarian la creciente productividad y el desarrollo gigantesco del industrialismo. Sería, según palabras de A. Smith, una consecuencia del cambio, actividad inherente a la sociedad humana.

Para Marx, sin desdeñar estos factores, el hecho fundamental es la producción de mercancías, el valor de cambio. Puede existir división del trabajo sin que indefectiblemente ello conduzca a la producción de mercancías, tal como va a realizarse en el MPC. No es extraño, que para Marx, el nuevo régimen de producción aparezca como «un inmenso arsenal de mercancías» (Marx, 1978). De los dos valores que las mercancías encierran, Marx se desentiende del valor de uso, para centrarse en el valor de cambio. En el régimen de producción de mercancías, hecho necesario pero no suficiente en el MPC, éstas son fabricadas para ser cambiadas, después de ser puestas en circulación. El intercambio se producirá mediante una nueva mercancía: el dinero. El régimen de producción de mercancías establece, pues, el proceso M-D-M compuesto de la fase de venta M-D (mercancía-dinero) y compra D-M (dinero-mercancía). Este proceso de producción y funcionamiento aleja al productor del momento de la consumición del producto (fábrica para vender), a la vez que homogeiniza a todas las mercancías entre sí, permitiendo su comparación mediante la mercancía dinero.

El siguiente paso lo da Marx para establecer la conexión entre la producción de mercancías y la generación de capital. El primitivo ciclo de producción $M-D-M$ se transforma en D-M-D, cambiando el origen y el final del mismo. El primer ciclo (M-D-M) comienza y acaba en la mercancía y su fin último es el consumo o valor de uso, mientras que en el segundo el motivo fundamental es el valor de cambio. El esquema real de este segundo ciclo es $D-M-D$ ', siendo $D^{\prime}>D$, lo que supone que el capitalista produce mercancias que luego vende a mayor precio con la única finalidad de aumentar el valor de su capital. El incremento es lo que Marx denomina plusvalía o plusvalor. Este aumento de valor proviene, según Marx, de una retribución inferior de la fuerza de trabajo o capital variable. En otras palabras, el obrero debe aumentar su jornada de trabajo en beneficio del capital. La jornada se divide, así, en dos partes: el trabajo necesario y el trabajo excedente.

En el segundo volumen de El Capital, Marx comienza estudiando de manera más detallada el ciclo capital-dinero. El ciclo completo estaría 
integrado por tres fases diferentes. En la primera, «el capitalista aparece en el mercado de mercancías y de trabajo como comprador; su dinero se invierte en mercancías, recorre el acto de circulación D-M" (Marx, 1978). La segunda fase la constituye el proceso de producción, el resultado es una mercancía de mayor valor que la composición de las iniciales (M...M'), mientras que en la tercera, el capitalista retorna al mercado como vendedor; sus mercancías se convierten en dinero ( $\left.M^{\prime}-D^{\prime}\right)$. Para Marx, el verdadero momento de producción de valor corresponde a la segunda fase.

El verdadero objetivo del capital es su reproducción ampliada. El capitalista, según Marx, no se queda con el plusvalor de la fuerza de trabajo para consumir sino para aumentar su capital. Su fin no seria, pues, el valor de uso sino acumular. La abstinencia obtiene al final su premio: el éxito social. Por este motivo, el estudio de la reproducción simple (sin aumento de capital) lo realiza Marx como paso obligado por el desenmascaramiento del verdadero proceso de reproducción ampliada. El capital se reproducirá con mayor rapidez, cuanto más reducido sea el tiempo total que tarda en producirse la plusvalia y que comprende, tanto el tiempo de producción como el de circulación, estando, así, de nuevo en condiciones de volver a ser invertido. De las tres fases de la reproducción, el tiempo de producción suele ser el más reducido, debido al progresivo aumento de la productividad, mientras que el tiempo de circulación absorbe la mayor parte del tiempo total, sobre todo, en la venta, la parte más difícil de la metamorfosis. De aqui la importancia de disminuir al máximo el tiempo de circulación. La función comercial y los gastos de transporte son analizados por Marx, fuera de la fase productiva y son concebidos, no como un efecto útil deliberado sino como un mal inevitable, destinado a limitar al máximo el tiempo de rotación del capital.

El tercer volumen de El Capital lo dedica Marx al análisis de la ley de tendencia descendente de la tasa de ganancia y las crisis del sistema capitalista, así como las formas de contrarrestarlas. La ley ha sido muy criticada y continúa siendo motivo de polémica, como reconoce $M$. Castells en una de sus obras directamente relacionada con el tema (Castell, 1978).

No podemos terminar de exponer la visión del planteamiento teórico marxista sin hacer referencia a otro de sus pilares básicos: la cuestión del estado y la lucha de clases. El análisis de Marx en El Capital quedó reducido al nivel económico del MPC. Los otros niveles, político-jurídico e ideológico no pudieron ser tratados por Marx, aún cuando los tuviera en proyecto. De ello no debe deducirse que los mecanismos económicos 
de acumulación del capital, tal como Marx los expuso en El Capital, puedan verificarse sin interferir el resto de los niveles estructurados.

Según la teoría marxista, la noción del estado aparece consustancialmente con el nacimiento de las clases sociales en la sociedad. Frente a otras concepciones, que lo consideran como un árbitro en el enfrentamiento de clases, la teoría marxista lo concibe como un órgano que "apenas creado se independiza de la sociedad, tanto más cuanto más se va convirtiendo en órgano de una determinada clase y más directamente impone el dominio de esta clase" (Marx, 1978). Pero veámos, cual es el concepto de clase social, verdadero agente social a considerar en el análisis marxista. Las clases sociales, como señala N. Poulantzas "son conjuntos de agentes sociales determinados, principal, pero no exclusivamente, por su lugar en el proceso de producción, es decir, en la esfera económica» (Poulantzas, 1977). La composición de las clases ha ido transformándose desde el primitivo estadio capitalista hasta el momento actual de forma paralela a la creciente división del trabajo que se ha operado en la sociedad. Ya no puede hablarse únicamente de relación de propiedad, para expresar la posición de una clase en el entramado social, sino su situación respecto a las relaciones de producción.

El papel asignado al estado consiste en atemperar los enfrentamientos de clase, facilitando la reproducción del sistema social, tanto a nivel económico (asegurar la acumulación del capital y la reproducción del trabajo en las formaciones sociales donde predomine el MPC), como en las demás instancias, política y jurídico-institucional. El primitivo reduccionismo de Marx en dos clases enfrentadas entre sí (capital y proletariado) se ha visto ampliado hoy con un mayor fraccionamiento, donde "la teoría marxista de las clases sociales distingue igualmente fracciones y capas de clase, según las diversas clases, a partir de diferenciaciones en lo económico y el papel, muy particular aquí, de las relaciones políticas e ideológicas" (Poulantzas, 1977). El funcionamiento de los aparatos del estado reflejaría la situación de la lucha de clases en una formación social determinada.

Como punto final de esta breve exposición, sobre el significado de los conceptos estado y clase social, debemos resaltar que el objetivo principal de la teoría marxista continúa siendo el de transformar y superar la sociedad actual mediante la lucha política, por la emancipación de la clase social explotada: el proletariado. En este sentido, la afirmación realizada por Marx y Engels en el Manifiesto de que el objetivo inmediato de los comunistas continúa siendo el derrocamiento de la dominación burguesa y la conquista del poder político por el proletariado, es aún válida. Las diversas estrategias elaboradas desde el siglo pasado para 
su consecución han dado lugar a diferentes tipos de marxismo práctico, cuyo análisis no interesa en este contexto.

Para concluir, vamos a analizar cual es el significado de lo urbano dentro del planteamiento teórico marxista expuesto anteriormente. Uno de los puntos de concordancia de todos los autores marxistas que han tratado el tema espacial es la imposibilidad de encontrar una teoría específica del espacio al margen de una teoría general de lo social. Esta circunstancia, unida al limitado crecimiento experimentado por las ciudades en aquel momento, explica un cierto desinterés en el tratamiento del tema urbano en los primeros momentos del desarrollo teórico marxista.

Más interesados por desvelar los mecanismos de la sociedad y del propio MPC a un nivel abstracto, el nivel espacial quedaba relegado a un segundo plano, en aquellos limitados casos en que el tema quedó planteado. Para Marx y Engels la separación «existente entre el campo y la ciudad, que caracteriza a todas las sociedades desde la antigüedad hasta el periodo del moderno capitalismo es a la vez la expresión y la base de la división del trabajo" (Saunders, 1981: 18). Sin embargo, el contraste entre el campo y la ciudad significaba más un objeto de estudio propio de los modos de producción anteriores al capitalismo, que de éste último. Según Marx, «la disolución del modo de producción feudal y la transición al capitalismo encontró en la ciudad un sujeto con identidad propia. La ciudad rompió el sistema feudal medieval, transcendiéndolo de forma que se convirtió en un sistema parcial con fuerza coherente, capaz de mostrar la existencia del sistema global y además de destruirlo" (Lefebvre, 1972: 71). Por el contrario, el MPC se asienta sobre la nueva forma de producción de mercancias. La ciudad desempeña un papel secundario, de aquí que «las nuevas manufacturas hubieran sido construidas en los puertos marítimos de exportación o en lugares del campo alejados del control de las antiguas ciudades y de su régimen gremial (Marx, 1978: 638).

Aunque Engels hace una brillante descripción de las condiciones de miseria de la clase trabajadora en uno de los bastiones de la revolución industrial: Inglaterra, el mismo sugiere, que «el problema de la vivienda que afectaba a los trabajadores y a una parte de la pequeña burguesía en las ciudades modernas es uno de los innumerables males de importancia menor y secundaria que resultan del MPC. Para su solución sólo existiría un medio: eliminar definitivamente la explotación y la opresión de la clase obrera por la clase dominante» (Engels, 1977: 15).

No es de extrañar, que fuera imposible para Marx en 1877 aceptar la ciudad y el campo como conceptos y categorias autónomas, legadas por la historia, para permitir engendrar el tiempo histórico al nivel de la inte- 
ligibilidad teórica. "Estas categorías debian subordinarse a categorías más generales, salidas por una parte de rasgos más comunes en toda sociedad (la producción, el consumo y su conexión interna), y por otra parte de rasgos específicos de la sociedad moderna" (Lefebvre, 1972).

De todo cuanto llevamos expuesto, cabe deducir que no existe en el trabajo de Marx y Engels unas bases suficientes para el desarrollo de una teoría especifica de lo urbano. Sin embargo, el explosivo crecimiento experimentado por las ciudades durante el presente siglo ha permitido reconocer su importancia como lugar de concentración de la producción y el consumo y el lugar por excelencia donde se realizan los ciclos de la reproducción, más complejos que los de la producción, a los que envuelven. No es de extrañar, pues, la aparición de nuevos autores, que desde los planteamientos clásicos de la tradición marxista han intentado facilitar la comprensión de los complicados procesos sociales que subyacen en la ciudad. Su análisis será objeto de apartados posteriores.

\section{El paradigma de Max Weber y el tratamiento de la ciudad}

El planteamiento teórico de Max Weber supone un giro de ciento ochenta grados respecto al sostenido por Marx. En primer lugar, Weber "pretende delimitar un objeto de análisis, separando lo científico de la política y los hechos de los valores. Se trataria, pues, de hacer un esfuerzo por deslindar ambos planos, el de ciencia social (ordenamiento conceptual de los hechos); pero inevitablemente también de política social (la exposición de los ideales)" (Weber, 1973: 49), sin que lleguen a mezclarse y confundirse. M. Weber es consciente de la dificultad y admite que los valores influyen a la hora de "seleccionar el objeto de conocimiento de una realidad empírica, caótica e infinita, por lo que resulta necesario acotar una parte para constituirla como objeto de conocimiento... pero evitando la confusión y explicitando los ideales que se confiesan" (Beltrán, 1978: 417). En contra de Marx, M. Weber cree en la posibilidad de elaborar una ciencia social desde una perspectiva no comprometida políticamente.

El concepto clave de la sociología weberiana es la suposición de la existencia de un individuo libre, cuya conducta exterior en relación con otros está motivada por factores racionales. Así, cualquier concepto deducido de la realidad social como clase social, estado... etc., no debe ser concebido como un ente social con vida propia, sino como el conjunto de individuos que lo integran. Por este motivo, cualquier explicación de una 
determinada acción social, concebida siempre en un sentido subjetivo, debe buscarse por la confluencia de diversos factores externos. "No hay, en efecto, para Weber una determinación del proceso histórico por la economía, ni siquiera en última instancia. Lo que si hay es una pluralidad de factores causales. Cual sea la articulación y/o el peso específico de estos factores es temia de investigación empírica, pero, por el momento, ya que reconocer que, a este respecto, hay, si, explicaciones especificas convincentes o persuasivas, pero no hay teorías generales satisfactorias. Esto no remite sino, simplemente, a constatar la pluralidad e independencia o autonomía recíproca de aquellos factores, y tratar de descubrir de qué forma se articulan entre sí, con objeto de explicar fenómenos específicos, tomando estas explicaciones como elementos de referencia para teorias de un orden de generalización mayor, es decir aplicadas a campos de fenómenos cada vez más amplios" (Pérez Díaz, 1980: 71).

Max Weber pretende superar desde su planteamiento el dualismo positivismo-historicismo que enfrenta a dos concepciones radicalmente divergentes. Frente a la postura positivista que emplearía un método generalizante, fundado en la abstracción, apto para expresarse con precisión matemática, particularmente en la física, y la historicista, propia de las ciencias de la cultura, trabajando con un método individualizante, dependiente de la intuición, apto para comunicar la significación, particularmente en la historia, se trataría de buscar un conocimiento más perfecto de los objetos sociales que explique al mismo tiempo, el significado particular y la ley general del acontecer social. La solución es hallada por Weber en la construcción de los tipos ideales. Según el propio autor «estos esquemas de interpretación no son simplemente, como se ha dicho, hipótesis análogas a las leyes científicas hipotéticas. Pueden funcionar como hipótesis de acontecimientos concretos. Por este motivo, si una ley de la naturaleza hipotética fracasa definitivamente en un solo caso, colapsa de una vez y por todas como hipótesis. Las construcciones de tipo-ideal de la economía política, sin embargo, no pretenden una validez general, mientras que una ley de la naturaleza tiene que tener esta pretensión si no quiere perder su significación" (Jiménez Blanco, 1978: 374). Estos tipos-ideales pueden ser individuales (capitalismo, burocracia... etc.), no denominados así por su referencia a un fenómeno individual, sino por su relación con una época histórica determinada, y genéricos, de carácter ahistórico y que sirven para especificar los elementos a partir de los cuales los tipos individuales son construidos.

Max Weber pretende demostrar que la elaboración de estos tipos ideales o categorias de análisis no suponen un corsé que limite la libertad humana. Asi se manifiesta al señalar "que la creencia de que, en cual- 
quier zona del conocimiento, los postulados deterministas incluyen el postulado metodológico de establecer categorías y leyes como la única pretensión, constituye tan gran error como la presunción que sostiene lo contrario que una creencia metodológica en el libre albedrio debe excluir la aplicación de categorías y reglas para la conducta humana. No existe ninguna base para la creencia de que el libre albedrío humano tiene que estar conectado con una específica incalculabilidad o en cualquier manera con cualquier clase específica de irracionalidad objetiva de la acción humana. Hemos visto que lo contrario es lo que acontece" (Jiménez Blanco, 1978: 378).

El tratamiento del tema de la ciudad es limitado en la obra de $M$. Weber. Siguiendo con la metodología implícita en su obra, Weber considera la ciudad, como una construcción válida para un momento particular de la historia, centrándose sobre todo en la ciudad europea medieval y su importancia en el desarrollo del capitalismo, verdadero objeto de estudio del autor.

La ciudad debe ser concebida con un doble carácter, económico y político. Desde el primer punto de vista, la ciudad es el lugar de mercado permanente, donde la población satisface unas necesidades de intercambio. A ella habría que añadir la capacidad de administrar un presupuesto de ingresos y gastos. La especificidad de la ciudad de occidente sería la constitución de una comunidad, que para Weber debe estar marcada por un conjunto de rasgos, lo que le permite construir otro de sus tipos ideales. "Son ellos: 1) una fortificación, 2) un mercado, 3) un tribunal judicial autónomo, 4) una forma relativa de asociación y 5) una autonomía, al menos parcial, y por tanto, una administración dirigida por autoridades en cuya selección participen los burgueses» (Weber, 1958).

Este tipo de ciudad ideal contrasta para Weber con la ciudad antigua, o con la ciudad oriental y asiática, donde la comunidad como tal no existía, donde el concepto religioso no cristiano ayudaba a la permanencia de las estructuras tribales o de clan. El concepto de ciudad, como lugar de asociación, sólo se produce para Weber en el occidente medieval europeo.

El limitado tratamiento al tema urbano que caracteriza la obra de $\mathrm{M}$. Weber le acerca a Marx, asi como su semejanza en el análisis histórico de la ciudad, como lugar de desarrollo del capitalismo moderno. "Ninguno de ellos, considera a la ciudad como una importante área de estudio. Para Marx, porque la base esencial de la división campo-ciudad hay que buscarla en el establecimiento de las relaciones capitalistas en el conjunto de la sociedad. Para Weber, porque la ciudad no constituye la 
base de la asociación humana. Ambos, dudan de la posibilidad de construir una teoría del urbanismo de las sociedades capitalistas" (Saunders, 1981: 35).

\section{El hecho urbano en el paradigma durkheimniano}

La definición que $\mathrm{E}$. Durkheim ha dado de la acción social difiere considerablemente de la de $\mathrm{M}$. Weber. Para Durkheim, la acción social consiste en "unas maneras de obrar, de pensar y de sentir, externas al individuo y dotadas de un poder coercitivo en cuya virtud se imponen a él" (Durkheim, 1965: 8). De ello cabe deducir, que Durkheim se aleja del criterio subjetivo de los individuos como participantes de la acción social, para centrarse en la conciencia colectiva transmitida de generación en generación, que coacciona y modela a la conciencia individual.

E. Durkheim se sitúa claramente en la línea del positivismo francés. Buscando un objeto de estudio, que asegure la objetividad y el empirismo necesario a todo conocimiento científico, considera que «los fenómenos sociales son cosas y como cosas deben ser tratados... Es cosa, en efecto, todo 10 que es dado, todo lo que se ofrece o, mejor aún, se impone a la observación. Tratar los fenómenos como cosas equivale a tratarlos como data que constituyen el punto de partida de la ciencia" (Durkheim, 1965: 35). Por ello Durkheim "asignará a la sociedad y, en particular, a los hechos sociales una existencia y una realidad independientes de los individuos que la componen, en lugar de limitarse a consignar la pluralidad y la complejidad de los niveles de análisis de la realidad social" (Pérez Díaz, 1980: 85).

Una vez fijado el objeto material de análisis y la cosificación como realidad tangible de los hechos sociales, la teoria sociológica para E. Durkheim debe ser construida inductivamente por medio de la observación. Ello es posible de efectuar porque aunque los individuos cambien, continúan manteniéndose los efectos del hecho social. "Si los individuos que componen una sociedad cambian de un año a otro, sin embargo, el número de suicidas es el mismo". ¿Pero como medir la esencia fundamental de estos hechos sociales? Durkheim supone que existe una relación fundamental entre lo que puede ser directamente observado y lo que define el hecho social en sí, pudiéndose utilizar indicadores capaces de medirla. 
“Dos principios básicos sirven para establecer un nexo de relación causa-efecto:

1. Que la causa determinante de todo hecho social debe ser buscada entre los hechos precedentes y no entre los estados de conciencia individual.

2. Cada efecto procede de una única causa. Si aparecen varias causas, ello significa que varios fenómenos deben ser explicados" (Durkheim, 1965: a).

El método a utilizar para el descubrimiento de las causas sociales es el de la variación-concomitante. El propio autor se manifiesta así al señalar que solo existe una manera de demostrar que un fenómeno determinado es la causa de otro: comparar los casos en que ambos están presentes o ausentes, y comprobar si las variaciones que presentan en diferentes combinaciones de circunstancias indican que uno depende de otro. Esta afirmación abre la posibilidad de utilizar las correlaciones observadas para expresar relaciones de tipo causal.

Quizás sea El suicidio la obra en que mejor ilustra Durkheim los principios metodológicos expuestos en las reglas, demostrando que "actos tradicionalmente considerados como estrictamente íritimos, circunscritos al fuero interno $y$ ajenos a toda explicación social, pueden ser analizados sociológicamente" (Giner, 1982: 613). El carácter social del suicidio obedece a causas de origen sociológico. Utilizando un abundante material estadístico, Durkheim dedujo la correlación existente entre religión y suicidio. Con valores extremos, a un lado y otro del espectro se encuentran los librepensadores y los judios y en medio protestantes y católicos. También aparece en un mayor grado en los solteros que en los casados, lo que permite al autor sacar conclusiones sobre la influencia de la anomia y la falta de lazos afectivos más profundos, como la causa del mismo. Por todos estos motivos, Durkheim concluye que el suicidio puede ser tratado como una "cosa" y que es por tanto un objeto de estudio de la sociología.

El mismo método se repite en el análisis del fenómeno religioso. En Las formas elementales de la vida religiosa, Durkheim postula que la religión es una cosa social, rechazando los planteamientos de tipo psicologista e individual. Analizado el material empirico de una sociedad primitiva australiana, llega a la conclusión de que en los momentos de concentración con otras personas, el hombre trasciende su propio yo personal, de manera que las creencias, ideas y prácticas religiosas simbolizan al grupo social, convirtiéndose Dios mismo en una representación colectiva de la propia comunidad. 
Desde el punto de vista de la aportación de Durkheim al análisis del fenómeno urbano, La división del trabajo puede ser considerada como su obra principal. El planteamiento de Durkheim respecto a la ciudad es dual. Por una parte, el terreno de la vida verdaderamente moral sólo comienza allí donde se inicia el campo de la vida colectiva. Durkheim opone a las sociedades de solidaridad mecánica, formadas por individuos iguales y semejantes como los eslabones de una cadena, frente a las sociedades de solidaridad orgánica basadas en la división del trabajo, con diferentes órganos, cada uno de ellos con un papel a desempeñar. "Este paso de un tipo de sociedad a otra lo explica Durkheim, de una parte, por el acercamiento material de los individuos, que se realiza a través de la transición del nomadismo a la agricultura, de la formación de las ciudades y del crecimiento del número y la rapidez de las comunicaciones; y, de otra, por el aumento del volumen de la sociedad que multiplica las relaciones intrasociales" (Remy y Voye, 1976: 257). En consecuencia, se considera a la ciudad como elemento clave para comprender el paso de la sociedad de un estadio a otro, al favorecer el desarrollo de la división del trabajo.

Para investigar las causas y la marcha de la división del trabajo de la estructura moral de la sociedad, Durkheim eligió el sistema del derecho. Las sociedades primitivas pueden ser definidas por un derecho represivo, donde el individuo no existe absolutamente como tal y cualquier conducta que se separe del comportamiento esperado es castigada brutalmente. Por el contrario, en las sociedades modernas el hombre está ligado a la sociedad por lazos indirectos por medio del derecho contractual. Este tipo de ley es un indicativo de la solidaridad derivada de las diferencias complementarias de los individuos. Para Durkheim, el incremento de la densidad material, unida directamente a la ciudad, puede conducir al de la densidad moral, aunque, en algunos casos anormales, la división del trabajo no produzca solidaridad y deba ser mantenida por la coacción y la represión. La guerra de clases sería concebida de esta manera, como una división coactiva del trabajo impuesta por la sociedad civilizada. Desde esta perspectiva, la concepción durkheimniana se aleja del organismo y del funcionalismo, donde los diversos órganos sociales funcionan siempre de manera integrada y complementaria. En consecuencia, además del reconocimiento de lo urbano como una fuerza positiva para el desarrollo de la libertad individual, queda asociado con los aspectos patológicos de la ciudad moderna.

En resumen, Durkheim "se refiere a la cuestión urbana de dos formas diferentes. Primero, como una condición históricamente importante para el desarrollo de determinadas fuerzas sociales (al crear la concen- 
tración material estimula la división del trabajo, lo que facilita el desarrollo que rompe los lazos con la moral tradicional). En segundo lugar, la ciudad moderna favorece el desarrollo de la desorganización patológica que refleja el estado anómico de la sociedad moderna" (Saunders, 1981: 47).

\section{LAS PRIMERAS APORTACIONES DE LA CIENCIA SOCIAL AL ANÁLISIS DEL ESPACIO URBANO}

Hemos tenido ocasión de exponer en el apartado anterior que las aportaciones de los principales padres de la Sociología moderna no llegaron a cuajar la elaboración de una teoría acabada sobre la ciudad. Como consecuencia, los primeros frentes de la incorporación de la teoría social al estudio del fenómeno urbano, tendrían lugar, bien dentro del marco ecológico de carácter biologista, característico de la tradición evolucionista, entonces dominante, o bien a partir de la concepción culturalista de la sociología urbana clásica, con el planteamiento dualista campo-ciudad donde se contraponen lo rural y lo urbano como dos formas culturales radicalmente diferentes. Ambas concepciones llegarían a dominar durante mucho tiempo el tratamiento teórico-social de la ciudad.

Únicamente el paradigma de E. Durkheim influiria de forma decisiva en el planteamiento metodológico utilizado por los ecólogos urbanos de la Escuela de Chicago, al permitir establecer una relación directa en el estudio del comportamiento humano, entre las fuerzas ocultas del mundo subsocial y su objeto directo de análisis: la comunidad. Por su parte, las aportaciones teóricas de K. Marx y M. Weber quedarían oscurecidas en un primer momento, aunque serían retomadas con fuerza a partir de los años sesenta.

Mayor trascendencia tendría, para el desarrollo de esta primera etapa del estudio de la ciudad, la aportación de la escuela sociológica alemana, uno de cuyos autores fundamentales, G. Simmel, marcaría la pauta al exponer la importancia de la concentración espacial en la transformación de las relaciones sociales. La influencia en $L$. Wirth seria decisiva en el intento de construir, dentro de la nueva perspectiva culturalista, una teoría atemporal de la ciudad. Además, el crecimiento experimentado por las ciudades a principios del siglo xx constituyó una motivación fundamental en el enorme interés despertado en aquellos años por el estudio del fenómeno urbano. La importancia de ambos fac- 
tores se pone de manifiesto en la afirmación de J. Remy y L. Voyé cuando señalan que: "uno de los grandes interrogantes de los años veinte en los Estados Unidos venía constituido, sin duda alguna, por el brutal crecimiento de las ciudades; y en la medida en que un cierto número de investigadores de la Escuela de Chicago había estudiado en Alemania o, al menos, había leído los trabajos sociológicos de la Escuela alemana, era perfectamente lógico esperar que el enfoque adoptado por ésta volviera a aparecer en la manera en que estos sociólogos iban a abordar la cuestión urbana" (Remy y Voye, 1976: 199).

De todos los autores alemanes, es, sin duda, G. Simmel quien abordó el tema con mayor profundidad. Puede considerársele precursor de la escuela de Chicago a través de su alumno R. E. Park, quien se dedicó a sistematizar e investigar sobre sus ideas. El espacio físico, según Simmel, no tiene en si mismo ninguna importancia sino es como soporte o lugar donde los seres humanos interactúan. El mismo señala que el espacio es una forma que en sí misma no produce efecto alguno. El espacio encierra diversas cualidades que influyen en las relaciones de los individuos sociales, facilitando su socialización. Entre estas cualidades, cabe destacar la exclusividad que define una relación entre un organismo social y el territorio sobre el que se asienta de manera única y la divisibilidad en zonas separadas por fronteras, en las que "el limite no es un hecho espacial con efectos sociológicos, sino un hecho sociológico con una forma espacial" (Simmel, 1977: 236). La existencia de barreras físicas facilita la delimitación de las zonas sociales diferenciadas, pero no es la causa de la misma. Estas ideas serían, más tarde, sistematizadas en la investigación llevada a cabo en el Chicago de los años veinte, y servirían de base a la definición de las áreas naturales, como células básicas de la organización social contenida en la ecología urbana. La riqueza del pensamiento de Simmel le llevó a adelantar muchas de las ideas que formarán parte del cuerpo de doctrina de la sociología urbana clásica.

En otro orden de cosas, es interesante expresar alguna de las ideas de Simmel acerca del condicionamiento de las grandes urbes sobre el comportamiento social humano. En su obra Metropolis and mental life, Simmel muestra los efectos que presenta sobre la comunidad humana el paso de las formas de vida integrada, propia de las comunidades tradicionales, a la vida en las grandes urbes, propia de una sociedad industrializada y burocratizada. De aquí nacerían todos los desequilibrios psicosociológicos del hombre moderno, que nos acerca a la visión dicotómica rural-urbano de la sociología urbana que tendremos ocasión de exponer más adelante. Es la vida de la gran ciudad lo que produce la 
desorganización y ruptura de la comunidad tradicional, característica de un medio rural tradicional y la posterior reorganización de la vida social en sub-comunidades donde el hombre busca aquellos lazos que le unen al grupo y que responden a necesidades de naturaleza social.

Como resumen, podemos indicar que en Simmel se encuentran gran parte de las ideas básicas que caracterizan a la sociología y ecología urbanas, dos disciplinas cuyas raíces se entrecruzan desde el momento de su nacimiento, ofreciendo nuevas aportaciones y perspectivas al estudio urbano.

\section{La ciudad como forma cultural}

La tradición cultural anglosajona ha producido siempre una imagen de la ciudad como contraposición a la del campo. Mientras la primera idea encerraba dentro de sí la acumulación de todos los vicios y males de la sociedad moderna, el último aparecía adornado por todas las virtudes de la vida rural.

Este nuevo enfoque en el tratamiento de la ciudad parte de la dicotomia rural-urbano ideada por Tönnies. Una vez establecidos los campos de estudio diferentes y justificado el porqué de la diferencia de comportamientos humanos en ambos medios, el objetivo se centra más en analizar las relaciones sociales urbanas de forma espacial, que en establecer una conexión científica entre los diversos elementos que componen el medio ecológico de la ciudad.

Lo que contiene, en realidad, este planteamiento y el de otros autores es una teoría de carácter social. Participa de ella el mismo E. Durkheim con su teoría de los estadios de la sociedad, que analizamos en el apartado anterior. Aunque se intente establecer una separación meridiana entre dos conceptos antagónicos, este tipo de trabajos está falto de una teoría específica del significado de lo urbano y de lo rural. Una importante excepción lo constituiría, sin embargo, el intento realizado por $L$. Wirth.

La aportación teórica de Wirth enlaza directamente con las ideas de Simmel. En su ya famoso artículo "El urbanismo como modo de vida», Wirth intentó sistematizar una teoría que recogiera las formas especificas y fundamentales de lo urbano. De la importancia del trabajo de Wirth nos da cuenta el comentario de M. Castells a su obra, cuando, habida cuenta de las diferencias ideológicas que separan a ambos autores señala: 
«Se trata probablemente del esfuerzo teórico más serio que jamás se haya hecho en el seno de la sociología para establecer un objeto teórico (y por consiguiente, un campo de investigación) específico de la sociología. Los ecos, treinta y tres años después, continúan dominando la discusión" (Castells, 1979: 97).

Según Wirth el «rasgo que distingue al modo de vida del hombre de la edad moderna es su concentración en agregados gigantescos que irradian las ideas y prácticas que llamamos civilización" (Wirth, 1962: 7), aunque su idea básica, a lo largo de todo el trabajo, será encontrar el concepto de lo urbano, no encerrado en una cultura o momento histórico determinado, sino como una idea general válida para todos los tiempos.

¿Cuáles son pues, para Wirth, las características que identifican la ciudad? La respuesta la da el autor cuando manifiesta que "el problema central del sociólogo de la ciudad es descubrir las formas de acción y organización sociales que, de modo típico emergen alli donde se da el establecimiento relativamente permanente y compacto de grandes cantidades de individuos heterogéneos. Debemos también inferir que el urbanismo asumirá formas más características y extremas en la medida en que se dan las condiciones con las cuales es congruente. Así, cuanto más grande, más densamente poblada y más heterogénea sea una comunidad, más acentuadas estarán las caracteristicas asociadas con el urbanismo" (Wirth, 1962: 20). Son, pues, estas tres características: tamaño, densidad y heterogeneidad, las que explicarían el comportamiento específico de los individuos en el medio urbano.

Las razones, que utiliza Wirth para convencer, enlazan directamente con el planteamiento de la obra de Simmel. El aumento cuantitativo en el número de individuos que componen una colectividad involucra un cambio en las relaciones sociales. Debido a ello, "la multiplicación de personas en un estado de interacción bajo condiciones que hacen imposible su contacto como personalidades completas produce esa segmentación de las relaciones humanas, interpretada, a veces, por los estudiosos de la vida mental de las ciudades como una explicación del carácter esquizoide de la personalidad urbana" (Wirth, 1962: 24). Esta segmentación separa a los individuos y produce unas relaciones caracterizadas por los contactos de tipo secundario y no primario; contactos, estos últimos, que caracterizan el mundo rural. Estos contactos que Wirth define, como impersonales, superficiales, transitorios y segmentados serían los responsables del modo de vida urbano.

El aumento de la densidad, otro de los rasgos urbanos, introduce los mecanismos propios de la segregación social. En estas circunstancias, la 
competencia por el espacio es grande, de modo que cada área tiende a ser usada de manera que produzca el mayor provecho económico. Así pues, la ciudad determina un doble proceso en la reconstrucción de unas nuevas relaciones sociales. Por una parte, produce la disgregación de los individuos respecto de la primitiva unidad rural, pero permite su integración en un mosaico de sub-mundos diferenciados.

Pero debido al tercer rasgo que caracteriza al urbanismo, estos lazos son, a veces, débiles y poco duraderos. Según Wirth, es "la interacción social existente en el medio urbano entre tal variedad de tipos de personalidad la que tiende a destruir la rigidez de las líneas de casta y a complicar la estructura de clases, produciendo así un entramado de estratificación social más diferenciado y ramificado que el que se encuentra en sociedades más integradas" (Wirth, 1962: 29). Esta estratificación social es poco rígida, produciéndose una alta inestabilidad y movilidad en la escala social, así como una débil integración con una parte determinada de la ciudad.

Como vemos, L. Wirth caracteriza al modo de vida urbano por los rasgos básicos que definen la urbanización. En resumen, un nuevo tipo de individuo social de carácter esquizoide y segmentario surge en este marco. La gran heterogeneidad que caracteriza a la ciudad y que se deriva de los diversos roles sociales procedentes de la división del trabajo separa a los individuos entre sí, pero los agrupa de forma diferenciada dentro de la ciudad. En estas ideas, ya adelantadas en parte por Simmel, se apoyarán gran parte de los posteriores análisis sociológicos sobre la ciudad.

Un apoyo importante a las ideas expuestas por L. Wirth en su obra fue el trabajo realizado por Redfield en la península de Yucatán, que dio origen a la teoría de Folk-Urban-Continum. Este planteamiento supone una separación de lo folk o tradicional frente a lo urbano o moderno. Dentro de una tradición de tipo antropológica, la sociedad folk se caracterizaria por ser una sociedad aislada y homogénea, con un gran sentido de la solidaridad de grupo. En ella lo sagrado domina lo secular y la economía se encuentra alejada del mercado. En contraposición, lo urbano concentra en sí la individualización, la secularización y la heterogeneidad. El paso de un estadio a otro no se verifica sino de forma contínua, según el grado de evolución social. En resumen, que puede encontrarse entre los diversos asentamientos humanos y sus relaciones sociales una variación gradual que puede ser explicada en términos de diferencia de tamaño y densidad, así como por su grado de heterogeneidad social, tal como de forma teórica había adelantado Wirth en su obra. 
Las críticas a esta visión de lo urbano se produjeron, tanto en el terreno práctico como en el teórico. El trabajo desarrollado por Lewis en Tepoztlan, uno de los lugares donde Redfield había elaborado veinte años antes su teoria del continuo rur-urbano, ponia de manifiesto la falta de armonía que debia presidir las relaciones rurales. Se podía encontrar, tanto reminiscencias de cultura rural entre los inmigrantes de una gran ciudad, como, por el contrario, formas de vida urbana en el campo, derivadas ambas, de la integración de las diversas formas ecológicas dentro de la misma sociedad.

La critica teórica a las teorías de Wirth y Redfield no provienen tanto de considerar la falsedad de sus apreciaciones, sino de la relativa falta de interés del objeto de estudio seleccionado. "En otras palabras, el tamaño de los asentamientos humanos es un factor entre los muchos que pueden tener algún efecto en el modelo de las relaciones sociales, y parece poco justificado aislarlo como objeto de estudio intensivo y especializado" (Saunders, 1981: 109).

\section{La aportación ecológica al estudio de la ciudad: la ecología urbana}

El extraordinario crecimiento demográfico experimentado por la ciudad de Chicago y la amalgama de etnias y culturas que se vieron obligadas a convivir con una gran proximidad espacial, convirtieron a la ciudad en un magnífico laboratorio social. El conocimiento directo y minucioso de esta realidad, por parte de los sociólogos que componen la escuela de Chicago, les iba a permitir la construcción de modelos sobre la diferenciación residencial de la ciudad, sostenida por una teoria explicativa basada en el biologismo. La aparente simplicidad de algunas conclusiones, el excesivo peso dado al factor biológico y la generalización de la validez del análisis a otras ciudades, iban a ser los puntos flacos de ataque al pensamiento de la escuela. Pero pasemos a exponer las ideas básicas en que se basa el pensamiento de los ecólogos urbanos.

En general se puede definir a la ecología humana como una rama de la sociología que estudia la relación entre la comunidad humana y su medio. De acuerdo con la definición, el objeto de análisis de la ecologia urbana será la comunidad y no la sociedad. B. J. Robson en su obra Urban Analysis, nos delimita el significado y alcance de ambos términos tal como fueron utilizados por Park en su visión ecológica de la ciudad: 
“En consecuencia, para acomodar los factores sociales y sub-sociales, construyó el marco conceptual de la ecología humana sobre una distinción fundamental entre los conceptos de 'comunidad' y 'sociedad', que debían ser considerados como aspectos diferentes de la vida humana; aspectos tan distintos, que el estudio de la comunidad quedaría incluido en la ecología, mientras que la sociedad sería objeto de tratamiento de la psicología social. Esta distinción se basaba en dos niveles diferentes de la actividad humana: el biótico y el cultural» (Robson, 1969: 30).

Además de la influencia ejercida por los sociólogos de la escuela alemana sobre los ecólogos de la escuela de Chicago, dos nuevos autores deben ser añadidos a la lista: los de Charles Darwin y E. Durkheim. Toda la construcción teórica de Park se sustenta en la analogía que establece entre el comportamiento de la comunidad humana y el de las comunidades animales y vegetales respecto al medio. A este respecto, Park señalaba que «el principio activo de ordenación y regulación de la vida en el terreno de la naturaleza animada es, como la describe Darwin, la lucha por la existencia" (Park, 1936). A este nivel, el individuo humano es considerado como los animales y las plantas en la lucha por la adquisición de las circunstancias más favorables para desarrollar su vida. EI nivel cultural, aquel que confiere a las personas atributos sociales, es abandonado conscientemente del análisis. El propio Park era consciente de esta limitación y admitia que en la sociedad humana, la competencia está limitada por la costumbre y la cultura.

La distinción entre el mundo biótico y cultural y entre comunidad y sociedad, clásica de la ecología humana, tiene motivaciones claramente metodológicas. La selección de la comunidad como objeto de estudio debe ser comprendida como un intento de limitar el análisis de la complejidad social a un campo más fácil para la investigación. Siguiendo el planteamiento teórico de Durkheim, Park concibe a la sociedad como una "cosa", que puede ser directamente observada de la realidad. "La investigación empírica puede comenzar con el estudio de la comunidad, porque ello constituye el marco en el cual la sociedad se desarrolla y porque es más fácilmente visible y por tanto más manejable mediante el análisis estadístico. A partir de aquí, debería ser posible descubrir regularidades entre las diferentes comunidades y en consecuencia desarrollar hipótesis y generalizaciones científicas" (Saunders, 1981: 57). La medición podría, además, ser realizada mediante la correlación ecológica, desempeñando la misma función que la variación concomitante de Durkheim.

Una vez centrado el estudio en el nivel biológico de la existencia, los ecólogos de la escuela de Chicago se dedicaron a analizar la distribución 
de las comunidades humanas en el espacio, estableciendo, en sentido durkheimniano, la relación existente entre el nivel biótico y su objeto empírico de análisis: la comunidad. Estas comunidades son concebidas como "áreas naturales" localizadas espacialmente. La delimitación de estas áreas ha dado lugar a amplias discusiones, dentro del mismo grupo de autores ecologistas. Para algunos, la diferenciación debe establecerse según el uso del suelo, delimitando su contorno por las líneas de transporte o diferencias topográficas. Para otros, eran más importantes los rasgos culturales que los físicos y serían la composición racial, lingüistica y profesional los elementos básicos de la delimitación. Park, desde una posición ecléctica, definiría el área natural como una unidad geográfica distinguible por su individualidad física y por las características sociales y económicas de su población.

Todos los procesos biológicos reconocidos en el mundo subsocial son adaptados al estudio del comportamiento humano. Veámos cuales son estos procesos. El primero y fundamental es el concepto de competencia. Según Timms, "el proceso de competencia impersonal proporciona el marco de la estructura ecológica" (Timms, 1976: 154). Esta competencia tiene lugar por la localización más ventajosa de las diversas actividades económicas y en cuanto al lugar más deseable para la residencia. De esta manera, la competencia por el espacio lleva a la segregación de los distintos tipos de actividades y personas en la ciudad, organizando su estructura interna. Este planteamiento acerca las posiciones ecológicas y economistas que se derivaban de los principios de la economia.

Este proceso competitivo por el espacio toma como referencia central el CBD, área donde los precios del suelo son máximos, y determina una gradación hacia el exterior. El mecanismo de los precios del suelo actúa como elemento diferenciador y "son estos valores del suelo los que determinan la localización de las instituciones sociales y de las empresas privadas" (Park, 1936: 25). En una segunda etapa del desarrollo de la teoria ecológica, A. H. Hawley recogió el testigo de los ecólogos clásicos y sistematizó el análisis de la relación entre la accesibilidad al centro y la distribución de los valores del suelo urbano.

La renta va a desempeñar un papel fundamental en la competencia que se establezca entre las diferentes unidades familiares. El resultado, como expresa el propio Hawley, es la segregación.

El segundo proceso, adaptado del mundo sub-social, y que interviene en la estructuración de las comunidades urbanas es el de la «do- 
minación». El propio Robson nos hace una descripción comparativa entre el comportamiento del mundo vegetal y el humano:

«Un segundo proceso es el de la 'dominación', que es uno de los conceptos fundamentales de los ecólogos vegetales. Entre los diferentes tipos de plantas existentes, una especie ejerce una influencia dominante, controlando las condiciones ambientales frente a otros tipos de especies... De la misma manera, en el interior de la ciudad, el CBD se constituye en el elemento dominante del complejo urbano, desde el momento en que la competencia entre las diversas actividades se establece por la ubicación en el mismo. Esta competencia determina la elevación de precios en el centro, lo que afecta a la disposición del resto de los elementos dentro de la estructura de la ciudad. Incluso, dentro de áreas más localizadas, tipos particulares de actividad ejercen su dominación. El área de más alto estatus es dominada por la gente de alto nivel de renta que resiste la posible invasión de la gente de nivel inferior; las áreas industriales son dominadas por aquellas industrias que por su carácter repelen el desarrollo de la función residencial. En este sentido el 'slum' es visto como aquella área de mínima capacidad de atracción que recoge los residuos de aquellos elementos de la ciudad, que por su bajo nivel de competencia, no pueden aspirar a ocupar otros lugares más ventajosos» (Robson, 1969: 9).

Por último, el concepto de «invasión-sucesión» es también propio del mundo vegetal y es aplicado al mundo subsocial humano. Las plantas, por su actividad transforman el medio en que viven creando las condiciones para que otras plantas puedan crecer y desarrollarse. La invasión por la nueva especie, puede convertirla en el elemento dominante, desplazando a las anteriores en un proceso contínuo de cambio. La aplicación del proceso a las comunidades humanas, fue realizado por los ecólogos clásicos en relación a la invasión de áreas residenciales por el comercio y negocios y de áreas residenciales de mayor estatus por otras de nivel de renta más bajo. En Chicago, además, la invasión de un área, ocupada por un grupo étnico mayoritario, por otro diferente producia nuevos ejemplos del proceso de invasión y del establecimiento del nuevo grupo invasor.

Una de las manifestaciones concretas de la aplicación de los principios de dominación central, segregación, invasión y sucesión fue el modelo de diferenciación zonal de la ciudad elaborado por Burgess. La estructura espacial de Chicago y de otras ciudades americanas era el resultado de un crecimiento de la población y su expansión en anillos hacia el exterior era provocado por el envejecimiento gradual de las áreas interiores y la invasión de las áreas próximas por los grupos de 
estatus inferior. Según Burgess, este proceso daba lugar a cinco zonas concéntricas, ocupada cada una de ellas por grupos de población diferenciada.

Al modelo de Burgess le sucedió la construcción de otro nuevo, el de Hoyt, que presenta rasgos comunes con el anterior. La diferencia fundamental se basa en que Hoyt reconocía la existencia de zonas de naturaleza sectorial y no circular, como resultado del comportamiento residencial de las clases de alto estanding social. Además, según sus propias palabras «el movimiento del área de alto nivel de renta es en cierto sentido el más importante, desde el momento en que tiende a empujar al crecimiento de la ciudad en la misma dirección" (Burgess, 1961). Hoyt aporta, igualmente, un modelo dinámico, que presenta la formación de un área de alto nivel social en la proximidad de la zona de comercio y de oficinas del CBD, alejado de la zona industrial, situada en la posición opuesta. Cuando la ciudad crece, el sector residencial de renta elevada se expande hacia el exterior, axialmente, según las líneas de transporte que facilitan su comunicación con el centro, mientras que los otros sectores lo hacen igualmente hacia afuera, produciendo una segregación sectorial.

En su planteamiento original, Hoyt exponia la existencia de factores dinámicos que favorecian una expansión rápida de la ciudad hacia el exterior. Entre ellos cabe destacar la gran corriente migratoria que invadía las ciudades americanas y el deterioro del CBD que impulsaba a la clase superior al movimiento hacia el exterior. El mecanismo de la expansión, que se deduce del de invasión - sucesión, difiere del propuesto por Burgess. Los nuevos edificios construidos para la ocupación por los grupos de alta renta, se encuentran situados en los límites de su antiguo sector. A medida que estas áreas crecen hacia afuera, los grupos de rentas baja e intermedia pasan a ocupar las viviendas abandonadas por los grupos de renta superior. El proceso es diferente, al producirse la filtración de los grupos sociales inferiores, con posterioridad al abandono del sector por los grupos de mayor estatus.

Una parte de las críticas se dirige hacia aspectos rígidamente geométricos contenidos en los modelos. Sin embargo, es necesario indicar en descargo de sus autores, que ya ellos concebian su realización como construcciones ideales, que resumen tendencias generales del comportamiento y no como modelos que hubiera que interpretar con excesiva severidad.

Otras críticas, como la de J. A. Quinn, se dirigieron a señalar la particularidad de presupuestos que subyacian en la ciudad de Chicago, 
lugar clave de la investigación, y la imposibilidad de generalizar la validez de los resultados a otras ciudades. Estos presupuestos son: la existencia de un crecimiento masivo de la población por inmigración, lo que conduce a un crecimiento muy rápido de la ciudad; un núcleo central dominante en la misma; un amplio conjunto de empresas comerciales e industriales y por último, como más importante, una libertad de mercado donde la competencia impersonal pueda desarrollarse plenamente.

Otros ataques a los modelos hacian hincapié en la arbitrariedad de la delimitación de zonas y sectores. Esta postura puede centrarse en la figura de P. Hatt, cuyo trabajo realizado en el área de Seattle, ponía en cuestión la división zonal realizada por Burges. Hatt encontró que cuando los datos relativos a los valores de renta se aplicaban a la población agrupada en sub-áreas en número reducido, las áreas naturales se reducian con una cierta facilidad, mientras que si estos valores se reflejaban sobre un mapa en unidades de tamaño inferior, solamente dos áreas homogéneas polarizadas podian ser puestas de manifiesto, quedando en el intermedio una amplia área mayoritaria de carácter muy heterogéneo. Según sus conclusiones «las áreas naturales son homogéneas en la ficción... casi creando una realidad donde no existe" (Hatt, 1946).

Según estos resultados Hatt consideró que estas áreas sociales se definían sobre la base de construcciones estadísticas y su delimitación y localización dependería enteramente del problema que se analizara. Estos planteamientos adelantaban, en parte, la delimitación sobre áreas sociales que iba a surgir a partir de los años cincuenta.

Por último, queremos señalar la aparente paradoja que resultaba de la existencia de dos modelos, que reflejaban dos estructuras completamente diferentes de la ciudad. Parecia evidente, que ambas no podian ser ciertas a la vez, y que la validez de una de ellas debía invalidar automáticamente a la otra. Uno de los trabajos más lúcidamente realizados para resolver esta situación fue el de Anderson y Egeland. Usando los presupuestos contenidos en el análisis de áreas sociales, estos autores mostraron la existencia de más de una dimensión básica en la diferenciación de la ciudad. La confusión había sido posible, según ellos, porque Hoyt habia basado su investigación en los valores de la renta y de las casas, mientras que Burgess lo había hecho sobre las densidades y tipología de viviendas. Ello ponía de manifiesto, la existencia de una distribución sectorial según las rentas económicas y una distribución zonal según estadio ocupado en el ciclo de vida familiar. La aparente contradición quedaba, de esta manera resuelta. 
Las críticas a los principios ecológicos clásicos se produjeron, primero de forma parcial, más tarde buscando una nueva teoría general que explicara la diferenciación residencial de la ciudad. La teoría de las Áreas Sociales, nacida en los años cincuenta, pretenderá convertirse en una alternativa válida al estudio de la estructura residencial urbana, pero veamos alguna de estas críticas y los nuevos planteamientos que surgen con el enfoque de los valores sociales.

\section{La crítica de los principios ecológicos clásicos: el enfoque de los valores sociales}

Los principios contenidos en los planteamientos de los ecólogos clásicos fueron pronto contestados por su concepción determinista y limitadora de la realidad. Ya en la última década de los años treinta y comienzo de los cuarenta tuvo lugar una severa reacción contra ellos, destacando los trabajos de M. Aliham y W. E. Gettys.

El primero critica, como insostenible, la posición dualista de los ecólogos humanos al aceptar los conceptos de comunidad y sociedad, divorciados entre sí. Para esta autora, la lucha por la vida no podia reducirse al nivel biológico, porque tenía lugar en la sociedad y era realizada por seres humanos con conciencia y deseo de control y de cambio de su medio ambiente. Pero su oposición aún mayor se deriva de la relación que se establece entre el concepto de comunidad, como construcción ideal abstracta de las particularidades del mundo asocial humano y la comunidad como un objeto visible de fácil investigación empírica. En otras palabras, se pone en tela de juicio la metodologia durkheimniana de carácter positivista, donde se identifican de forma directa las fuerzas ocultas que organizan el mundo subsocial con su referencia empírica directa.

En resumen, puede observarse que a pesar de la construcción del "área natural", como un concepto que sirviera de base para establecer un puente directo entre la teoría y la investigación práctica, la mayoría de los estudios realizados se refieren a estudios estadísticos de poblaciones y a la representación espacial de los resultados, la mayoría de las veces muy variables, según la unidad administrativa seleccionada para el análisis.

La aportación de W. Firey se basa en la introducción de factores de tipo cultural, ampliando, así el espectro de elementos explicativos. El sistema de valores o creencias acerca del mundo no puede ser compren- 
dido, según Firey, de forma semejante en todos los lugares, sino que varía según cada país, cada grupo, e incluso cada persona. Estas concepciones, que se desarrollaron en el exterior del campo económico, tuvieron gran influencia en la elaboración de una nueva línea de investigación teórica, de base behaviorista, que tuviera en cuenta la capacidad de elección de las personas y de los grupos sociales.

El estudio realizado por $W$. Firey en la ciudad de Boston tenia por objetivo poner de manifiesto la importancia de este tipo de factores frente a los seleccionados habitualmente por los ecólogos urbanos. Firey eligió tres áreas, dos de clase social elevada y otra de clase inferior, aunque su trabajo se centró únicamente en las áreas de estatus más alto por la dificultad de obtener información de tipo no-económico en el área de estatus inferior. Las dos áreas estudiadas fueron las de Beacon Hill y Boston Common. Según la teoría ecológica clásica, Beacon Hill debía haber sufrido la invasión y el posterior declive, debiendo ser ocupado por una población de clase inferior. Sin embargo, la extraordinaria fuerza manifestada alli por las tradiciones sociales y culturales, determinó la resistencia de sus habitantes a las tendencias del cambio. El caso de Boston Common era similar. La ciudad ha crecido alrededor de este pequeño núcleo, que sobrevive desde los primeros tiempos de la colonización, a pesar del grave problema del tráfico generado y de las tendencias contrarias a la eficacia económica que representa.

Las conclusiones del trabajo de Firey señalan el papel desempeñado por los valores culturales e ideológicos frente al énfasis atribuido por los ecologistas a los valores del suelo como mecanismo determinante de la diferenciación de la ciudad.

\section{LAS RECIENTES APORTACIONES DE LA TEORÍA SOCIAL EN EL CAMPO DE LO URBANO}

\section{En enfoque gerencial. Los agentes productores del espacio urbano en el sistema socio-espacial}

Durante el amplio espacio de tiempo que transcurrió entre la finalización de la segunda guerra mundial y la década de los años sesenta, la sociología urbana se había convertido en una disciplina descriptiva, poco coherente y falta de un objeto específico de estudio teórico. La 
pérdida de la identidad propia era el producto del abandono, tanto de las teorías procedentes de la escuela de Chicago (a pesar del esfuerzo de A. Hawley para renovar los planteamientos ecologistas en una dirección funcionalista) como del progresivo descrédito de la teoría del continuo rural-urbano. En este ambiente, surgió, en estos años, junto al Análisis de Áreas Sociales, más afin al planteamiento positivista, una concepción de lo urbano desde una perspectiva más amplia, que trataba de integrar diferentes aspectos económicos, sociales y políticos en el espacio. La aportación, en este campo, de autores procedentes de la geografía, pone de manifiesto el cambio transcendental que se estaba ya operando en nuestra disciplina y en concreto en una de sus ramas: la geografía urbana, tradicionalmente al margen de los planteamientos más avanzados.

Una parte importante de estas nuevas aportaciones se han caracterizado por el intento de introducir el espacio en el análisis de los procesos sociales que definen el complejo mundo actual, así como por la búsqueda de un objeto específico de estudio que integrara el espacio urbano y la sociedad y diera coherencia a la sociología urbana.

La primera aportación de importancia surgió en el año 1967 con la publicación del libro de Rex y Moore, Race, Community and Conflict. En este trabajo, ambos autores "desarrollaron un marco teórico que representaba una fusión entre el trabajo de Burgess en Chicago y el énfasis puesto por M. Weber en la importancia de la acción individual en el hecho sociológico, y en este sentido, pusieron los fundamentos para una sociología urbana que podía integrar las relaciones sociales en una dimensión espacial» (Saunders, 1981: 110).

Debido a la influencia que las ideas de $M$. Weber han tenido en el desarrollo de esta nueva orientación del estudio de la ciudad conviene realizar, aunque con brevedad, una exposición de las mismas. Los dos principios básicos de la sociología política de Weber eran, como vimos, la no existencia de una relación directa entre poder político y económico, tal como desde siempre lo han entendido los marxistas, y que el modo de dominación política en las sociedades modernas es fundamentalmente burocrático. La concepción weberiana de términos como estado, clase social... etc., es básicamente diferente de la de Marx. Desde el punto de vista weberiano, el estado no es un ente social diferente, por encima de las determinaciones de los individuos, siendo capaz de imponer su control desde los propios individuos que lo dominan. El concepto de clase social queda alejado de las determinaciones sociales, derivadas de las relaciones de producción. No es algo que se impone al individuo por encima o más allá de su realidad, sino que queda delimitado por un conjunto de individuos con intereses similares, cuya situación semejante 
permite construir en unas circunstancias históricas determinadas un tipoideal (clase social), a quien referirse de forma coherente.

En consecuencia, para $M$. Weber, la relación de conflicto en la sociedad es una relación entre individuos, actores sociales confrontados entre sí, donde el poder de cada grupo es básico para comprender la marcha de la sociedad. Quien disponga de un privilegiado acceso a los instrumentos de poder del estado podrá ejercer la dominación sobre los demás y obtener una gran posición de ventaja. La autonomía del poder político y económico permite afirmar que no siempre las clases sociales, económicamente poderosas, controlarán el aparato estatal. Por tanto, la burocracia se convierte automáticamente en una de las principales fuerzas de la sociedad. ¿Y quien es capaz de controlar la maquinaria burocrática del estado? Según Weber, "este control es posible solo en un limitado número de casos, a las personas que no son técnicos especialistas" (Weber, 1968: 224). El control democrático es, pues, muy limitado, incluso en las sociedades capitalistas democráticas con existencia de una democracia formal. De esta manera, $M$. Weber construye otro de sus tipos ideales desde los cuales explicar el comportamiento social: el "corporatismo".

Bajo la influencia de las ideas de M. Weber, Rex y Pahl desarrollaron la tesis del "managerialismo». El objeto del estudio urbano se debería centrar, según ellos, en el conflicto que enfrenta a las diversas clases sociales en la competencia por los diferentes tipos de vivienda existentes en la ciudad, así como al papel desempeñado por los "managers" o gerentes en la localización y características de este bien escaso. La nueva tarea asignada a la sociología urbana sería, pues, "el estudio de los modelos de desigualdad social, tal como son afectados por el mercado (de la vivienda) y los procesos burocráticos" (Pahl, 1970: 53). Pero veamos más detenidamente el contenido de esta nueva aportación teórica.

La capacidad para competir en el mercado agrupa a los individuos en diversos grupos marcados por su diferente nivel de renta. Desde el momento, que un mismo espacio no puede ser ocupado por dos familias a la vez y que la desigualdad en la distribución espacial de la vivienda es característica específica del espacio, el conflicto se presenta como inevitable. Se supone que los diferentes actores sociales lucharán entre ellos por acceder a la vivienda mejor localizada y de calidad superior, así como que todos tienen un sistema de valores común y los mismos deseos y preferencias. Esta localización escasa y diferencialmente superior se identificaría con la vivienda suburbana, ya que, como señala el propio Rex, «el persistente movimiento que tiene lugar hacia el exterior justifica 
la adopción de un modelo en que la vivienda suburbana es un bien escaso y deseado" (Rex, 1968: 214).

La segunda hipótesis del planteamiento teórico de Rex y Pahl, supone que el mercado de la vivienda queda afectado por la intervención directa de los «managers". ¿Pero que agentes sociales quedan incluidos dentro de esta etiqueta? En el modelo más puro, desarrollado por Pahl, se excluyen todos los agentes pertenecientes al sector privado y aún dentro del sector público, se consideran únicamente aquellos funcionarios del gobierno municipal que asumen el control de acceso a los recursos locales. La justificación a la integración, únicamente, de este reducido grupo de individuos se basa en que los "managers urbanos juegan un papel crucial entre el estado y el sector privado, asi como entre la autoridad estatal central y la población local» (Pahl, 1970).

Las críticas surgidas en torno al primitivo planteamiento de Rex y Pahl fueron muchas y se derivaban de los más variados aspectos. En primer lugar, el concepto de clase social, a diferencia de la concepción marxista, se centraba en la esfera del consumo (en este caso de la vivienda) y no en la producción. En un contexto teórico, como el que Pahl y Rex se proponían, el problema surgía en el momento de construir los tipos ideales relativos a las diferentes clases sociales. El número de clases potenciales a definir según el criterio de la capacidad de renta económica podía ser infinita, desde el momento en que nunca existirian dos personas con la misma situación en el mercado. Se hacia imprescindible la delimitación, un criterio inequívoco para identificar empíricamente un número de grupos limitado y de características semejantes. En el primitivo trabajo de Rex y Moore, ambos autores llegaron a definir cinco grupos diferentes: inquilinos propietarios, arrendatarios de viviendas municipales, arrendatarios de viviendas privadas, propietarios de casa de huéspedes y arrendatarios de casas de huéspedes. Posteriormente, el número se aumentó a siete y más tarde a once. La mayor contradicción a la hora de definir las clases sociales surgía de la falta de coherencia existente entre el concepto teórico (definido a partir de la situación en el mercado de cada grupo) y el delimitado en la práctica (a partir del tipo de tenencia). Esta última clasificación se desvía del argumento teórico que suponía, que el principal proceso urbano se derivaba del conflicto entre las clases sociales de posibilidades económicas diversas, que desean el mismo tipo de vivienda.

También, en esta última proposición, los resultados empíricos obtenidos en la práctica contradecian el planteamiento teórico. Diversos estudios realizados ponían en evidencia que la' pretendida uniformidad de comportamiento de los diversos grupos sociales, considerados como con- 
sumidores, era errónea, y mientras que unos deseaban una localización periférica, otros preferían una localización centralizada. Además, la vivienda no era, únicamente, el único punto de referencia a la hora de seleccionar un lugar para habitar, sino que el acceso a otros bienes (como equipamientos, servicios, proximidad de trabajo... etc.) tenía una importancia decisiva, demostrando, así, la existencia de un mercado con unas variadas preferencias de los consumidores. Por otra parte, tal como fueron concebidos los grupos sociales por Rex y Moore, coincidian más con el concepto de "estatus social» tal como fue definido por Weber que con el de clase social propiamente dicha.

Las críticas hacia el papel desempeñado por los managers fueron, aún si cabe, más duras. El mantenimiento del modelo más puro, elaborado por Pahl, se hacía casi insostenible. La autonomía de funcionamiento y la influencia de las decisiones de los "managers" aparecian como desmesuradas. En consecuencia, la consideración de los managers urbanos como agentes independientes debía modificarse, por la importancia que debía concederse a otra serie de agentes y circunstancias, derivadas tanto del sector privado como público. Este hecho condujo a Pahl a «introducir dos importantes modificaciones en su último trabajo sobre el managerialismo. En primer lugar, él distingue sobre managers del sector privado y los del sector público local, restringiendo su definición de managers urbanos a esta última categoria. En segundo término, reconoce que los burócratas municipales deben operar bajo la influencia tanto del sector privado como del gobierno central. En este sentido, abandona su primitiva consideración de la independencia de los managers, mediatizados, tanto por las presiones del sector privado por aumentar sus beneficios o las necesidades sociales de los habitantes, como de otras demandas derivadas del gobierno central y la población local... Se deduce de todo ello, que una adecuada explicación de la desigual distribución de la vivienda en el sistema urbano debe ser conseguida únicamente, combinando un análisis del proceso de localización al nivel local con un análisis de la producción de recursos en la sociedad, considerada como un todo.

La consecuencia que puede deducirse de cuanto llevamos expuesto es que si la posición de independencia de los managers no puede ser sostenida y debe acudirse a la introducción de nuevos agentes, que expliquen desde distintos niveles (sector privado capitalista y papel del estado) la realidad de los hechos sociales, la teoría aún está sin desarrollar. En este sentido se manifiesta Williams al señalar "que el managerialismo no es una teoria, ni tan siquiera una perspectiva correcta, sino única- 
mente, un marco de trabajo para realizar el estudio" (Williams, 1978: 236). Una alternativa diferente provendrá del campo teórico marxista.

\section{La aportación marxista al estudio de la ciudad}

El punto de vista tradicional marxista de que la ciudad no debe ser considerada como un objeto de estudio con significación propia ha ido transformándose desde finales de la década de los sesenta. Este cambio no puede considerarse radical, ya que no se llegará a concebir lo urbano como un campo con autonomía total respecto al funcionamiento de una determinada sociedad. En este sentido se manifestaba $M$. Castells al señalar que "el espacio urbano está estructurado o sea, no se organiza al azar y los procesos sociales que se refieren a él expresan, especificándolos, los determinismos de cada tipo de cada período de la organización social» (Castells, 1979: 141). La subordinación de lo urbano a lo social queda expresado con suficiente claridad como para que "el urbanismo pueda ser considerado como una forma o modelo característico de los procesos sociales» (Harvey, 1979: 216).

El planteamiento teórico marxista continúa considerando como ideológicos el resto de los tratamientos dados al tema urbano. En este sentido, D. Harvey define la teoría contrarrevolucionaria como aquella que «impide automáticamente tanto la creación como la aplicación de una política viable. Por consiguiente, es un instrumento perfecto para no tomar decisiones, porque desvía nuestra atención de las cuestiones importantes a otras superficiales o inexistentes" (Harvey, 1979: 157). En resumen, aquello que no permite apuntar hacia las situaciones de injusticia y dominación social para superarlas. Se hace necesario, por tanto, desde esta perspectiva, superar una concepción de la ciencia que se queda en lo superficial, en las apariencias. No es extraño, que los principales ataques se dirijan hacia las limitaciones de los métodos más usuales en el tratamiento del fenómeno urbano, que se contentan con analizar los aspectos más formales, por ser aquellos más fácilmente identificables por los sentidos, y los que cierran el camino a una comprensión más profunda de la realidad. $H$. Lefevbre expresa de esta manera este pensamiento:

«El fenómeno urbano utiliza en primer lugar unos métodos descriptivos de gran variedad. La ecología describe el hábitat, las unidades de vecindad, las formas de relación. La descripción fenomenológica, más 
sutil, se ocupa fundamentalmente de las relaciones entre ciudadanos y el medio: estudia el entorno, las disparidades del espacio, los monumentos, las tendencias y los horizontes de la vida urbana. La descripción empirica insiste sobre la morfología; se interesa con exactitud por lo que contemplan y hacen las gentes en un marco urbano determinado. Estos métodos evidencian ciertos aspectos y rasgos del fenómeno urbano. Podemos preguntarnos si la utilización de estos métodos nos permitirá conocer dicho fenómeno urbano más exacta y profundamente. A partir de un determinado punto, la descripción, incluso muy meticulosa, no es suficiente. Nos hallamos en los límites de la mortologia y de la ecología" (Lefevbre, 1976: 20).

Se trataria, por tanto, de comprender que la realidad no puede conocerse únicamente a través de la experiencia sensible, sino contribuyendo a crear los conceptos que ayuden a conocer las relaciones fundamentales en que participan los individuos a partir del proceso de producción.

Sin embargo, no todos los autores marxistas que se han ocupado del tema urbano mantienen un punto de vista común respecto a la estrategia teórica y al momento de desarrollo actual de las relaciones de producción. Para $H$. Lefevbre, «el conocimiento del fenómeno urbano solo puede constituirse en ciencia en/y por la formación consciente de una praxis urbana que, con su racionalidad propia reemplace a la praxis industrial ya realizada... Esto supone, en primer lugar, la confrontación ya mencionada entre la ideología urbanística y la práctica urbana de los grupos y clases sociales; en segundo lugar, la intervención de fuerzas sociales y politicas; en tercer lugar la liberación de las capacidades de innovación sin excluir el utopismo más próximo a lo imaginario puro... Todo ello, pone de manifiesto la emergencia y la urgencia de una nueva práctica social, que ya no será la práctica de la sociedad industrial, sino de la sociedad urbana" (Lefevbre, 1976: 143).

D. Harvey difiere radicalmente del planteamiento de $\mathrm{H}$. Lefevbre al señalar, que si bien es cierto que "el urbanismo posee una estructura separada, con una dinámica propia... esta dinámica es moderada por la interacción y contradicción con otras estructuras. Decir que el urbanismo domina actualmente la sociedad industrial significa decir que las contradicciones entre el urbanismo como estructura en el proceso de transformación y la dinámica interna de la anterior sociedad industrial se resuelven normalmente a favor del primero. Yo no creo que esta afirmación sea realista" (Harvey, 1979: 327). Harvey continúa pensando que es el capitalismo industrial el que produce el espacio y que la sensación de una progresiva urbanización de la ciudad, si bien es cierta, consiste fun- 
damentalmente en un aumento del capital fijo, ligado a un proceso de acumulación, cuya dinámica está limitada y controlada por el propio capital industrial.

La concepción de lo urbano para Harvey enlaza con los planteamientos de Marx en El Capital. Las estructuras que dominan la producción industrial capitalista no solamente se reflejan en el espacio, sino que llegan a convertir el espacio en capital. El interés teórico de Harvey se centra en el análisis del proceso de urbanización que sigue siendo todavía impulsado por las necesidades del capitalismo. El gran desarrollo experimentado por las ciudades modernas y su compleja estructura interna no sería sino fruto de una creciente concentración de inversiones de capital fijo y de un modelo de circulación del plusvalor basado en la apropiación y en la explotación, cuya lógica sólo puede ser explicada desde la dinámica interna de la expansión del capital.

Semejante postura, respecto a $\mathrm{H}$. Lefevbre, mantiene $\mathrm{M}$. Castells al criticar las teorías expuestas por éste en La revolución urbana y $E l$ derecho a la ciudad. Para Castells, si el capitalismo industrial ha creado unas determinadas relaciones de dominación de unas clases sobre otras, en el actual entramado de la lucha de clases, estas relaciones no desaparecerán sin más. El derecho a una ciudad libre de la represión, en donde la vida cotidiana se convierte en obra, apropiación y valor de uso, es concebido por Castells como una visión utopista, que únicamente podría llegar en un proceso histórico de transformación de la sociedad, a través de una práctica política, dentro de la teoría marxista de los modos de producción, propia del materialismo histórico.

Si bien la metodologia marxista intenta establecer una relación entre los diversos niveles estructurales que componen la totalidad social (económico, político e ideológico), las aportaciones al estudio del fenómeno urbano se han centrado fundamentalmente en dos: aquella cuya concepción de la ciudad entronca en el ámbito del consumo con la reproducción de la fuerza de trabajo y aquella otra que concibe lo urbano como un elemento importantísimo en la acumulación de capital en el actual sistema del capitalismo monopolista de estado.

\section{a) La ciudad como unidad colectiva de consumo. La aportación teórica de M. Castells}

La contribución de M. Castells a la sociología de carácter marxista enlaza con el marco teórico de referencia de Althusser, derivado del es- 
tructuralismo aplicado a la epistemología marxista. De acuerdo con el mismo, los niveles económico, político e ideológico que componen un determinado modo de producción están relacionados entre sí de forma contradictoria y dialéctica, de manera que no necesariamente el nivel económico debe ser el dominante, estableciendo una determinación sobre los demás, sino que cada uno de ellos tiene una relativa autonomía. En los modos de producción anteriores al capitalismo, el nivel económico no había ocupado un lugar preponderante y así, el modo de producción antiguo se había caracterizado por el papel principal asignado al nivel político, mientras que en el modo de producción feudal este lugar destacado le correspondería al ideológico-religioso. Únicamente en el momento revolucionario del cambio social, el nivel económico desempeñaría una «determinación en última instancia», que explicaría la desaparición del modo de producción dominante ante su ineficacia para reproducir las relaciones de producción.

Es sobre esta base fundamental, derivada del materialismo histórico, como M. Castells pretende captar lo específico de las formas del espacio social. «En consecuencia, analizar el espacio en tanto que expresión de la estructura social equivale a estudiar su elaboración por los elementos del sistema económico, del sistema político y del sistema ideológico, así como por sus combinaciones y las prácticas sociales que derivan de ello" (Castells, 1979: 154).

Castells supone, pues, la existencia de tres sistemas independientes cuya organización en el espacio se realiza por medio de elementos fundamentales interdependientes. El sistema económico "se organiza en torno a las relaciones entre la fuerza de trabajo, los medios de producción y el no trabajo, que se combinan según dos relaciones principales: la relación de propiedad (apropiación del producto) y la relación de apropiación real (proceso técnico de trabajo)" (Castells, 1979: 154). Espacialmente, los elementos que componen el nivel estructural económico son: la producción, el consumo como forma de reproducción de la fuerza de trabajo y el intercambio, relación de los dos anteriores.

La articulación del sistema político-institucional en el espacio se "organiza en torno a dos relaciones esenciales que definen este sistema (relación de dominación-regulación y relación de integración-represión) y de los lugares así determinados... Por último, el sistema ideológico organiza el espacio marcándolo con una red de signos, cuyos significantes se componen de formas espaciales y los significados de contenidos ideológicos, cuya eficacia debe medirse por sus efectos sobre el conjunto de la estructura social» (Castells, 1979: 155). 
Aunque ningún elemento de los que integran los tres sistemas puede ser analizado al margen de los demás, el que posee un carácter más específicamente urbano, según Castells, es el relacionado con el consumo o la reproducción de la fuerza de trabajo. Al fin y al cabo, la producción posee una escala de organización más amplia, al menos regional, y para determinado tipo de relaciones incluso nacional o internacional. Por el contrario, el consumo se organiza, en cuanto a satisfación de las necesidades de la masa trabajadora (vivienda, hospitales, educación, comida..., etc.) en un espacio como mucho metropolitano. Por este motivo, Castells propone como hipótesis de partida que en las sociedades capitalistas avanzadas, el proceso que estructura el espacio sea el referente a la reproducción simple y ampliada de la fuerza de trabajo. En consecuencia, lo urbano quedaría integrado con la reproducción de la fuerza de trabajo y el espacio urbano con las unidades articuladas al consumo.

Uno de los problemas que Castells considera básicos dentro del consumo en la ciudad es la falta de una vivienda adecuada para la población trabajadora. La producción de viviendas sociales posee unas particularidades propias que la hacen ser abandonadas por el capital por falta de rentabilidad económica suficiente. La crisis que esta situación generaría, se traduciría en una inadecuada reproducción de la fuerza de trabajo, mostrando la contradicción existente entre el valor de uso y el valor de cambio. Pero, esta característica del modo de producción capitalista no quedaría reducida únicamente a este bien básico, sino que se ampliaria a todos los servicios paralelos que complementan las necesidades de los trabajadores, a saber: educación, asistencia médica, transporte..., etc. La consecuencia de ello, para Castells, es la necesaria intervención estatal como regulador de la cohesión social, lo que le convierte en uno de los pilares básicos de la reproducción de la fuerza de trabajo. Este es "ell motivo por el que el consumo llegaría a ser cada vez más colectivo y el sistema urbano resultaría progresivamente estructurado por la intervención estatal" (Saunders, 1981: 189).

$\mathrm{Si}$ bien Castells abandona deliberadamente uno de los elementos claves del análisis marxista, el de la producción y el papel desempeñado por el espacio urbano en la reproducción ampliada y en la acumulación del capital, no puede retrotraerse a introducir, en el esquema de «lo urbano" el problema del poder y la lucha de clases. Esta necesidad la reconoce el propio Castells al señalar que "el corazón del análisis sociológico de la cuestión urbana está en el estudio de la política urbana, es decir, de la articulación específica de los procesos designados como urbanos en el campo de la lucha de clases y, por consiguiente, con la 
intervención de la instancia política (aparato del estado) objeto, centro y blanco de la lucha política» (Castells, 1979: 290).

La teoría del estado y de las clases sociales que Castells utiliza es la desarrollada por N. Poulantzas, tal como el mismo reconoce al definir "las relaciones de poder como relaciones entre clases sociales y las clases sociales como combinaciones de lugares contradictorios definidos en el conjunto de la estructura social, concibiendo al poder como la capacidad de una clase o fracción de clase para realizar sus intereses objetivos, a expensas de las clases, o conjuntos de clases contradictorias, con quienes están en contradicción" (Castells, 1979: 289). Las contradicciones y luchas entre las diversas clases se expresan, en una coyuntura determinada, en una relación de poder respecto al aparato del estado. Se abandona la vieja idea de que el estado refleja de manera categórica la dominación de una clase sobre las demás, siendo, únicamente, fruto de la lucha de clases existente en un momento histórico determinado.

Planteado el problema de la ciudad, Castells distingue el nivel estructural del nivel conyuntural y en este sentido diferencia estructura de prácticas. É|, entiende por práctica urbana, toda práctica social relativa a la organización interna de las unidades colectivas de reproducción de la fuerza de trabajo o que, apuntando a los problemas generales del consumo colectivo elige como campo de acción las unidades urbanas (en cuanto que ellas son las unidades de estos procesos de consumo). Los dos tipos de prácticas definidas son la planificación urbana y los movimientos sociales urbanos. Ello representa, por un lado, «el estudio de la intervención de los aparatos del estado, en todas sus variantes, sobre la organización del espacio y sobre las condiciones sociales de reproducción de la fuerza de trabajo. Por el otro, el estudio de la articulación de la lucha de clases, incluida la lucha política, en el campo de las relaciones sociales" (Castells, 1979: 310).

Castells presenta el sistema de prácticas como definido por su pertenencia estructural, pero a su vez cuyos efectos secundarios expresan una autonomía relativa, capaz de definir de nuevo la situación más allá de su carga estructural... Estos efectos son capaces incluso de cambiar las leyes de la estructura. De esta manera, M. Castells sitúa en dos planos diferentes, la estructura como concepto teórico y la práctica como derivada de la situación coyuntural y más accesible a la investigación empírica. La relación de ambos planos queda un poco difusa en la obra del autor. ¿Pueden las contradicciones sociales urbanas trascender y articularse a la lucha de clases general que tiene lugar en la sociedad? Para Castells estas contradicciones sociales son: pluriclasistas en el sentido 
de que en vez de oponer directamente a las dos clases fundamentalmente antagónicas, redistribuyen las clases o fracciones de clase en términos opuestos que varían según la coyuntura, y secundarias, en el sentido que cuestionan directamente las leyes fundamentales del modo de producción.

Esta contradicción, entre la aparente debilidad de las prácticas sociales como elementos transformadores de la sociedad y su incidencia y eficacia en la lucha de clases general, la resuelve el autor diciendo que puede ocurrir que existan coyunturas en las que dicha contradicción se convierta en principal con respecto al criterio de desarrollo de la toma de poder.

La crítica al planteamiento de $\mathrm{M}$. Castells proviene, tanto del tratamiento del tema urbano como lugar de consumo, desligado del proceso productivo general, cuanto de su teoría de los movimientos sociales urbanos. Lojkine le ataca duramente por el intento de deslindar como «urbano" un campo específico de análisis, sugiriendo que la separación de las cuestiones de producción y consumo, acumulación del capital y reproducción de la fuerza de trabajo tiende a reproducir las concepciones tradicionales burguesas, que intentan analizar los problemas urbanos al margen de la política económica del capitalismo" (Saunders, 1981: 212).

En otros casos, la crítica se centra, no en la separación de la producción y el consumo, sino en la correspondencia establecida entre el término "urbano" y el consumo colectivo. En este sentido, se manifiesta $P$. Saunders al señalar que si bien es cierto que algunos bienes y servicios procurados y organizados por el estado tienen una referencia espacial (como la vivienda pública, escuelas, hospitales... etc.), otros no, con lo que el propio consumo funciona en un sistema más amplio que el delimitado por la ciudad.

Debido al énfasis de Castells en la relativa autonomia, así como en su metodología específica de investigación provenientes de la separación de estructuras y prácticas, algunos autores han llegado a entrever ciertos lazos con el planteamiento weberiano de la realidad social. El método propuesto por Castells de relacionar lo abstracto y lo concreto, la investigación empírica y la conceptualización teórica, parecería próximo a la construcción de tipos ideales de $\mathrm{M}$. Weber, deducidos de un determinado contexto histórico. Sin embargo, Castells nunca ha concebido las acciones humanas (prácticas) de forma voluntarista, por lo que su planteamiento se movería contradictoriamente entre un determinismo más propio de la teoría marxista y el papel asignado a los actores sociales, con una cierta autonomía para transformar la realidad. 
Por último, esta posibilidad de transformación social a partir de las prácticas sociales (tanto la planificación urbana como los movimientos sociales urbanos) no aparece definida con claridad en la obra de Castells. Faltaría por asignar el papel de estas prácticas en la lucha de clases a nivel del conjunto de la sociedad, así como su relación con el aparato del estado como reflejo de la situación de la lucha de clases en momentos históricos determinados.

\section{b) La economia política y la cuestión urbana}

Otro de los planteamientos de la teoria social marxista tiene lugar en un contexto más general, y en vez de establecer la conexión entre la ciudad y una determinada parcela del proceso productivo (en concreto el consumo) intenta relacionar el espacio (y dentro del mismo el espacio urbano) con la economía política.

Este nuevo intento de analizar el espacio urbano se desarrolla en dos esferas diferenciadas: en un primer nivel, económico, se trata de relacionar el espacio (necesariamente de forma global) con el proceso de reproducción del capital (necesidad básica para la reproducción del sistema productivo), mientras que en un segundo nivel, el político, el problema que se plantea es el de como el proceso de acumulación del capital se relaciona con la lucha de clases y el papel del estado. De esta manera, de las dos partes en que artificialmente y por motivos analíticos se puede subdividir el proceso de obtención de mercancias en la sociedad capitalista, la producción pasa a ocupar un lugar preferente, desplazando el consumo a un lugar secundario.

Desde este nuevo posicionamiento marxista, la ciudad desempeña un papel fundamental en el proceso de producción del MPC en una formación social determinada. Parece evidente, sin embargo, que el hecho urbano no ha estado indisociablemente unido a ningún modo de producción concreto. Por este motivo, parece interesante, disponer, aunque sea brevemente, de una perspectiva histórica que nos ayude a comprender la importancia de la ciudad.

En primer lugar, cabría preguntarse, cuando surge según la visión marxista, la ciudad en la historia y que papel desempeña en las diferentes fases históricas. Con respecto a la primera pregunta, la unanimidad es casi total, incluso entre autores no marxistas. Parece necesaria la existencia de un excedente agrícola para que surgieran las primeras formas urbanas. En este aspecto es clásica la obra de Gordon Childe al 
analizar, según los conocimiento empíricos que se disponen, las diversas circunstancias que debieron acontecer en la aparición del fenómeno urbano.

En general, toda la historiografía marxista, señala el momento de la apropiación del excedente por una casta militar y religiosa, el surgimiento de la ciudad y la diferenciación de clases sociales, como tres sucesos coincidentes en el tiempo.

La posterior evolución de la ciudad es tratada de forma diferente según los autores. $H$. Lefevbre ha expuesto su punto de vista en su obra La revolución urbana, donde nos plantea un eje de progreso del fenómeno urbano, que parte de la ciudad política, camina hacia la ciudad mercantil y posee un punto de inflexión de lo agrario hacia lo urbano, antes de transformarse en la ciudad industrial. Esta sería una fase previa, anterior a la urbanización total de la sociedad. Lefevbre describe el momento crítico en que lo agrario queda completamente subordinado a lo urbano, como:

«La implosión-explosión (metáfora tomada de la física nuclear), es decir, la enorme concentración (de agentes, de actividades de riquezas, de cosas y de objetos, de instrumentos, de medios, de posibilidades y de pensamiento) en la realidad urbana, y el inmenso estallido, la proyección de múltiples y disociados fragmentos (periferia, extrarradios, residencias secundarias, satélites, etc.)" (Lefevbre, 1976: 20).

David Harvey, uno de los autores que han intentado realizar un estudio del fenómeno urbano, dentro de las coordenadas expresadas por Marx en El Capital, nos propone sustituir los modos de producción del pensamiento clásico marxista por los que denomina modos de integración económica, social y política, presentes en la obra de Karl Polanyi. Existen para él, tres modos diferentes de integración: la reciprocidad, la redistribución y la integración por el mercado, que se hayan presentes en las diversas etapas históricas recorridas por la humanidad. Los dos primeros mecanismos de integración están presentes en todas las sociedades precapitalistas. En general, la reciprocidad está asociada exclusivamente con las estructuras sociales igualitarias, el intercambio de mercado se asocia exclusivamente con la estratificación, pero la redistribución puede existir tanto en estructuras sociales jerarquizadas como estratificadas. La sociedad basada en la reciprocidad se correspondería con lo que Marx denominó comunismo primitivo y su coherencia social es mantenida por la cooperación. En el caso de la redistribución, una pequeña élite se apro- 
pia de parte de la producción y manifiesta su poder mediante instituciones legales. El intercambio de mercado tiene lugar, según Harvey, cuando los mercados sirven para fijar los precios y coordinar las actividades económicas. A partir de este momento se abandona el valor de uso de las mercancías, ocupando el valor de cambio el lugar preminente. Son las condiciones propias de una sociedad capitalista, según podemos observar en palabras del propio Harvey:

«Por tanto, el foco de intercambio es más bien el valor de cambio que el valor de uso. En vez de vender mercancias, el dinero es utilizado para comprar mercancías que luego son revendidas (generalmente transformadas) para que produzcan más dinero. Este último proceso de circulación es el distintivo del comportamiento comercial, y es el modelo de circulación en el que se centra el análisis de Marx en El Capital»" (Harvey, 1976: 221).

Las sociedades igualitarias serian incapaces de crear el urbanismo, mientras que las jerárquicas producirian una estructura urbana de centros jerárquicos del género derivado de las teorías de Lösch y Chistaller. La ciudad capitalista conduciria inevitablemente a la concentración y a las aglomeraciones urbanas actuales.

¿Pero cuál es el papel asignado a la ciudad (y en general lo urbano) dentro del MPC? Ya tuvimos ocasión de exponer las ideas expresadas por Marx en El Capital, que la lógica del sistema capitalista se basa en la reproducción ampliada del capital. Desde esta perspectiva uel desarrollo de la aglomeración urbana vendría determinado por la constante tendencia del capitalismo a reducir el tiempo de producción y el tiempo de circulación del capital. La ciudad aparecería así como el efecto directo de la necesidad de economizar los gastos accesorios de producción, los gastos de circulación y los gastos de consumo con el fin de acelerar la velocidad de rotación del capital y por ende de aumentar el período en que el capital está produciendo" (Lojkine, 1979: 146).

Con anterioridad, la ciudad era concebida de forma parásita, aunque concentrara alguna actividad productiva. La industrialización cambiaría radicalmente el hecho urbano, transformando a la ciudad, que se convierte tanto en centro de producción como de extracción del plusvalor.

El mercado ya existía unido a la ciudad desde los primeros tiempos, pero cuando realmente dará lugar a un nuevo modo de producción será al concentrar el poder de fijación de los precios en una sociedad en que todo se transforma en mercancía. Una vez establecido este nuevo marco 
de funcionamiento, la lógica del sistema va a propiciar la progresiva producción de plusvalor y de acumulación de capital. El espacio va a desempeñar un papel importante, pues en «una economía capitalista, el plusvalor acumulado es en gran medida, utilizado para crear cantidades aún mayores de plusvalor. Este proceso no se da con la misma intensidad en todos los sectores o territorios de la economía capitalista. Su intensidad depende, entre otras cosas, del nivel de penetración del mercado en tal o cual sector o territorio. Es importante, por tanto, examinar los modelos espaciales y sectoriales de circulación del plusvalor conforme los beneficios son invertidos a fin de conseguir nuevos beneficios" (Harvey, 1976: 242).

¿Cuál es, entonces, el espacio que corresponde a la acumulación del capital? A partir del momento en que la cooperación de las fuerzas productivas humanas y materiales no se limita ya a la unidad física de la fábrica sino afecta, por mediación de la empresa combinada del grupo monopolista, al conjunto de un territorio nacional, luego de los conjuntos multinacionales, ya no se puede separar la concentración de los hombres de la de las máquinas, los lugares de acumulación de capital» (Lojkine, 1979: 317). No existe pues un espacio específico, aunque el armazón urbano en el estadio monopolista, aparece entonces ante todo con su red de ciudades medias, de metrópolis provinciales, nacionales e internacionales, como una distribución social y espacial de las diferentes condiciones generales de la producción, desde actividades industriales-portuarias de la industria pesada hasta los centros de investigación, gestión o informática.

Parece desprenderse de cuanto llevamos señalado que el principal papel que desempeñaría la ciudad sería favorecer la acumulación del capital. ¿Pero de qué manera? D. Harvey diferencia la existencia de tres circuitos donde el capital puede ser invertido y acumulado. El primer circuito sería propio del capitalismo industrial. En la producción de mercancias industriales, la ciudad ha favorecido, con la creación de grandes aglomeraciones, la disminución del tiempo de rotación del capital, y en consecuencia, el aumento de su acumulación. Sin embargo, el incremento del capital fijo dificultaría cada vez más la reproducción ampliada del capital a escala global. Esta dificultad reciente conduciría a la crisis, producida por una "tendencia a la sobreacumulación, debido a la imposibilidad de encontrar una salida rentable a la inversión y reproducción del exceso de capital producido" (Harvey, 1978: 104).

Harvey contempla la política llevada a cabo en USA después de la segunda guerra mundial, como una respuesta al gran aumento experimentado por la capacidad productiva desarrollada durante la guerra. El 
incremento del consumo (política keynesiana) sería la consecuencia de los nuevos campos abiertos a la inversión del capital en bienes productivos. Esta inversión no sólo se redujo a la producción de bienes de consumo industriales sino que además «el estado y el capital financiero facilitaron una inversión masiva en el circuito secundario. El efecto de todo ello fue que aparte de encontrar una nueva área de inversión como medio de evitar una crisis potencial de sobre-acumulación en el circuito primario, la inversión estimuló la demanda de productos del capital industrial. El 'boom' de la industria de la construcción ayudó a que se produjera el 'boom' del automóvil, el del suministro de energía, y así sucesivamente" (Saunders, 1981: 225).

La inversión de capital en infraestructura física ha significado una importante parte del circuito secundario del capital, tanto en capital fijo (fábricas, oficinas... etc.) como en el destinado al consumo (vivienda principalmente). Por su parte, la inversión en el circuito terciario (que no es el más relevante para D. Harvey), se produce bien en la investigación científica 0 en la tecnología (que ayuda al capital, revolucionando las fuerzas productivas), o por inversión en gastos sociales (que ayudan al capital mejorando la cualidad de la mano de obra por la educación, o controlándola por medio de la ideología y la coerción).

La posición de $D$. Harvey, centrada fundamentalmente en el problema de la acumulación capitalista, abarca únicamente uno de los aspectos del proceso urbano. Este argumento es defendido por Lojkine cuando manifiesta que la urbanización capitalista debe de ser entendida desde la doble vertiente del consumo (reproducción de la fuerza de trabajo) y de la producción. En este sentido, diferencia entre las condiciones generales de la producción necesarias para la reproducción del capital y los medios de consumo.

Entre estos últimos, no todos los gastos derivados del consumo pueden ser considerados del mismo tipo. Mientras que los gastos derivados de la educación, investigación y desarrollo tienen una componente productiva más próxima a los gastos de infraestructuras de carreteras, comunicación... etc., los provenientes de la salubridad de la población, equipamientos socio-culturales, transporte colectivo... etc., quedan relegados a un segundo plano y pueden ser considerados como no productivos. Para Lojkine, existe en el sistema capitalista una contradicción permanente entre las necesidades de reproducción del capital y las relacionadas con la fuerza de trabajo. Esta situación conduciria, según él, a una limitación de la inversión pública en aquellas zonas o ramas del consumo menos productivas, lo que explicaría el subdesarrollo creciente de las regiones menos dotadas de infraestructuras urbanas $y$, por otra 
parte, la congestión urbana, la gigantesca aglomeración de la megalópolis donde ya están concentrados los medios de comunicación y de consumo colectivo más variados y densos. Pero, incluso en las grandes aglomeraciones urbanas, el capital monopolista provocaría la segregación social de sus habitantes, en zonas muy desiguales en cuanto a calidad de vivienda y equipamientos.

En general, Harvey mantiene una postura similar, aunque pone un acento más positivo en las consecuencias que la inversión social del estado tiene para el aparato productivo. Por una parte, el valor deducido del capital (en forma de impuestos) que sirve para promocionar las infraestructuras sociales regresa a él, en la forma de una demanda efectiva para las mercancías que el capitalista produce. Únicamente la circulación del valor en las inversiones sociales daria lugar a un incremento del tiempo de circulación y supondría una pérdida en la posibilidad de aumentar la plusvalia. Pero, "las mejoras en las condiciones sociales pueden tener efectos a largo plazo. Mejoras en la calidad del trabajo a través de la educación y de la salud, así como de otros medios que afecten a la disciplina, trabajo ético, respecto a la autoridad... y además, pueden tener un efecto positivo en la producción de plusvalor" (Harvey, 1982: 401).

Quizá convenga detenerse, aunque sea brevemente, en la importancia que alcanza dentro de este planteamiento el problema de la vivienda. Hemos examinado en apartados anteriores, como autores como Rex o Castells han dado una gran importancia a este bien básico que enfrentaba a los grupos o clases sociales entre sí, lo que le hacía convertirse prácticamente en un objeto de estudio específico de la sociologia urbana. Sin embargo, un análisis del problema de la vivienda desde la perspectiva de la economía politica debe añadir el papel de esta mercancía urbana como forma de aumentar la plusvalía del capital.

Como cualquier otro bien producido, el análisis marxista considera a la vivienda una mercancía más, aunque con unas características determinadas. Debido a la lentitud de la fabricación, la tasa de rotación del capital invertido es muy baja, lo que produce un aumento de su precio, que deja fuera del mercado a una buena parte de la demanda (demanda no solvente). Esta situación obliga a la intervención del estado para permitir la posibilidad de obtener plusvalía en aquellos tipos de vivienda de inferior calidad. Otra de las limitaciones de la mercancia vivienda es la necesidad de disponer de suelo urbanizable que además de constituir otra mercancía peculiar (no reproducible y monopolizable), hace intervenir un nuevo agente social de carácter especular: los propietarios del mismo. 
«Estas peculiares necesidades de la circulación del capital han conducido a un sistema espacial de producción-realización que define nuevos roles para los agentes económicos. Propietarios que reciben rentas, urbanizadoras que reciben nuevos incrementos de rentas por sus mejoras realizadas, constructores que ganan el beneficio de su empresa, financieros que prestan dinero a un interés determinado y el estado que puede usar impuestos para inversiones que el capital no puede acometer" (Harvey, 1982: 395). Estos nuevos papeles económicos deben ser desempeñados de forma individual o combinada, siendo los promotores inmobiliarios los que se encargan de coordinar las diversas funciones para ofrecer en el mercado la mercancía terminada.

El análisis de la producción de viviendas desde la perspectiva de la acumulación del capital presenta una doble perspectiva. En primer lugar como parte importante de la reproducción de la fuerza de trabajo existiría una contradicción entre las necesidades del capital industrial de reducir los salarios de los trabajadores, y el elevado precio resultante de la mercancía vivienda. De todo eso serían culpables, en primera instancia, la elevada renta procedente del suelo (suma de las rentas de monopolio, absoluto y diferencial) y después la baja productividad del sector de la construcción (debido a la baja tasa de la composición orgánica del capital). Por ello, los propietarios del suelo, actuando en su propio interés inmediato y tratando de aumentar el volumen de renta de que se apropian, pueden forzar al capital a invertir en suelo, lo que provocaría problemas a las necesidades propias de la acumulación. De la misma manera, el reducido crecimiento en la productividad de la industria de la construcción llegaría a convertirse en un problema crucial para el capitalismo.

Desde la otra perspectiva, la larga duración del período de producción hace necesaria «la aparición de un capital de circulación que asegure el retorno a la forma dinero del capital productivo, antes del final del período de producción, es decir, una rotación normal del capital industrial» (Topalov, 1975: 47). La posibilidad para este capital de asegurar la producción de plusvalía es difícil, pero en determinadas circunstancias históricas se produce un flujo de capital industrial hacia el sector inmobiliario en condiciones suficientes de rentabilidad. Para ello es necesario, tanto la aparición del capital financiero, desligado de la producción industrial, y dispuesto a invertir donde la materialización coyuntural de la plusvalía sea más elevada, como la existencia de un flujo de suelo urbanizable abundante. Desde esta perspectiva, "si el capital industrial está interesado por ejemplo en que la renta del suelo sea débil, el capital 
financiero puede, por su parte, tener interés en liquidar los propietarios del suelo, apropiándose de la renta bajo otra forma" (Ascher, 1975: 29).

Por último, merece la pena hacer referencia a la importancia del estado y la lucha de clases dentro del contexto planteado de la acumulación de capital en la ciudad. Aunque D. Harvey no considera en detalle este problema, adelanta, sin embargo, algunos de los elementos claves de la intervención estatal. La principal sería su labor omnipresente para garantizar la libertad juridica de los individuos y mantener a la fuerza de trabajo como una mercancía, pero además a un nivel más particular promover la producción de mercancias (principalmente en la construcción) cuando los capitalistas son incapaces de abastecer el mercado, función vital para procurar las condiciones de la acumulación. También, planificar la economía espacial del capitalismo y regular la tensión existente entre la concentración y la dispersión geográficas. A través del patriotismo de un banco central, el estado juega el papel hegemónico de procurar el abastecimiento de dinero, así como el de centralizar la función impositiva... en fin, el estado se convierte en la institución central alrededor de la cual se forma la alianza de las clases.

La elaboración de una teoría de las clases sociales en el estado capitalista con referencia a la cuestión urbana existe únicamente a nivel de planteamiento inicial. La alianza de las clases, o de las fracciones de clase es dificil establecer en el marco urbano, así como la relación de estas uniones coyunturales respecto al estado de la lucha de clases general. Por una parte, el interés de los trabajadores, al presionar para la obtención de una vivienda propia, puede aproximarles a una clase social tan distante como el capital financiero, deseoso de poner en marcha el negocio inmobiliario. Mientras, por la otra, la separación entre los lugares de producción y consumo, puede dar lugar a que diferentes consumidores, trabajadores todos, estén enfrentados entre sí.

Por último, una novedad en los recientes planteamientos marxistas sobre la ciudad se derivan de la crisis del modelo territorial de concentración. Un modelo basado en la localización funcional de las actividades y población en base a criterios de segregación espacial, tendente a disminuir el tiempo de reproducción de la tasa de ganancia. «La crisis de ese modelo se expresa a la vez en el fenómeno del estancamiento, en el fenómeno de la inflacción estructural y en el fenómeno de la caída de la tasa de crecimiento de productividad, tres fenómenos, que fueron elementos determinantes en la crisis de modelo territorial basado en la concentración metropolitana» (Castells, 1982: 6). 
El nuevo modelo territorial capitalista se expresa en términos de descentralización y difusión urbana y productiva en el espacio, como nueva forma de recuperar la tasa de beneficio, puesta en entredicho con la concentración de las grandes aglomeraciones urbanas. La ruptura «del modelo de desarrollo cuantitativo" (Campos Venutti, 1985: 23) ha sido posible merced a las nuevas tecnologías de la información y el transporte que facilitan la deslocalización, permitiendo una reorganización del sistema productivo a escala mundial. El modelo de organización territorial que mejor respondería a las exigencias de la crisis económica se alejaría de la continuidad de los procesos de crecimiento de las tradicionales regiones industriales, para, abrir nuevas posibilidades a la acumulación de capital en organizaciones empresariales de menor tamaño, difundidas en el espacio. Esta situación implicaría la individualización generalizada del proceso de trabajo, con enormes consecuencias a nivel de la organización social y debilitamiento de las clases trabajadoras.

\section{CONCLUSIONES}

El enorme crecimiento experimentado por las ciudades desde comienzos de siglo ha sido una de las causas que más ha influido en el desarrollo de una teoría que tratara de comprender el fenómeno urbano en su creciente complejidad. Esta circunstancia explica que las aportaciones de los padres de la sociología moderna, como E. Durkheim, K. Marx y $M$. Weber relegaron la cuestión urbana a un segundo plano de sus preocupaciones teóricas.

No es de extrañar, que una de las primeras aproximaciones científicas al estudio de la ciudad proviniera del campo de la ecología, y ello por un doble motivo. La extraordinaria influencia de las ideas evolucionistas a lo largo de la segunda mitad del siglo XIX permitía considerar a la ciudad como un organismo vivo, capaz de adaptarse al medio en un proceso de continuo crecimiento. Por otro lado, la delimitación de un objeto de estudio propio: la comunidad, hacía posible el análisis objetivo y empíricamente verificable, dentro de la concepción positivista de la ciencia. Los ecólogos de la escuela de Chicago concentrarían, pues, los esfuerzos de la investigación teórica por dos caminos, a la vez complementarios: el descubrimiento de las áreas naturales, verdaderas células del organismo urbano, así como de los mecanismos (dominación competencia, invasión-sucesión, ... etc.) capaces de explicar la expansión de 
la ciudad en el espacio. El éxito de la ecología urbana, con una base teórica tan débil, basada en el biologismo más elemental, hay que buscarla en la elección de Chicago como área de estudio, cuyo crecimiento vertiginoso en tan corto espacio de tiempo, convirtió la ciudad en un verdadero laboratorio de la ciencia social urbana. Además, las ideas de competencia por el espacio armonizaban bien con la ideología dominante del capitalismo en su primera fase de comportamiento más económicamente liberal.

Cabe considerar el trabajo de G. Simmel y L. Wirth como el segundo intento de elaborar una base conceptual coherente, de carácter sociológico, para el estudio de la ciudad. A pesar de los puntos comunes que ambos autores presentan, existen, a la vez, rasgos diferenciados importantes. Mientras Simmel intentaba relacionar el efecto que las grandes aglomeraciones urbanas provocan en las relaciones sociales con la división del trabajo como uno de los factores claves de la sociedad mercantil moderna; L. Wirth limitaba su estudio al descubrimiento de las tres variables básicas que compondrían el urbanismo de todos los tiempos: tamaño, densidad y heterogeneidad de la población. La importancia desmedida concedida al efecto provocado por el tamaño de la ciudad sobre las relaciones sociales, así como la conclusión pertinente de separar lo urbano de lo rural, como dos formas culturales de vida contrapuestas fueron las dos consecuencias más importantes de esta nueva contribución teórica al estudio del fenómeno urbano.

Durante bastante tiempo, las aportaciones provenientes de la ecología urbana y de la sociología urbana clásica se convirtieron en los puntos de referencia obligados en el conocimiento teórico de la ciudad. Las nuevas coordenadas científicas, de carácter neopositivista sustituyeron el contenido sociológico de anteriores planteamientos por los principios de la economía neoclásica, introduciendo el análisis de lo urbano en la búsqueda de modelos equilibrados, dentro de una estructura espacial mononuclear, con el centro (CBD) como bien escaso y de mayor valor económico, lugar codiciado por los diferentes usos del suelo que componen la ciudad. Dentro de esta visión estructural-funcionalista de carácter económico, el intento realizado por A. Hawley para transformar, durante los años cincuenta, el planteamiento ecologista anterior, entronca con el paradigma funcionalista.

Las innovaciones en el tratamiento de lo urbano vendrian a finales de los años sesenta, cuando el objeto de estudio propio de la economía neoclásica comenzará a ser criticado por la rigidez en la concepción del comportamiento humano, dentro de los esquemas del "homo economi- 
cus". Además de las aportaciones de carácter behaviorista, que trataron de modificar el excesivo racionalismo económico del modelo anterior.

Los nuevos intentos de elaborar un objeto propio de la sociología urbana, diferente de los anteriores, enlazan con las primitivas ideas teóricas de K. Marx y M. Weber, en un momento de crisis social que hizo pasar a un primer plano las corrientes radicales de la ciencia social. La idea fundamental que distingue a este nuevo planteamiento teórico es la importancia atribuida a la acción de los grupos sociales en el espacio, caracterizada por el conflicto y el enfrentamiento de intereses. El espacio será considerado, en consecuencia, como un producto social y no como lugar de manifestación de la racionalidad económica.

La primera aportación en esta línea de investigación teórica adopta los principios de $\mathrm{M}$. Weber sobre el comportamiento de los grupos sociales en la sociedad, integrados éstos por individuos con capacidad de decisión propia. La importancia concedida por Weber a la burocracia, como un agente social con autonomía suficiente para mediar en los conflictos que enfrentan a los diversos grupos sociales que intervienen en la ciudad, permitió a Rex y Pahl la construcción del «managerialismo», planteamiento que define a los «managers" como los verdaderos agentes decisorios en el establecimiento de la función residencial de la ciudad, objeto de estudio básico de lo urbano. Su debilidad teórica proviene, tanto de la ausencia de un verdadero criterio delimitador de las clases o grupos que intervienen en la competencia por la vivienda dentro de la ciudad, como de la referencia, excesivamente simple, de considerar el espacio suburbano como único lugar deseado por cada grupo social. Además, el posterior reconocimiento de ambos autores, sobre el papel desempeñado dentro de la sociedad capitalista, por otros agentes que operan a un nivel superior que el propiamente local, supone de hecho, reafirmar las limitaciones y contradicciones de su planteamiento.

Tanto esta aportación teórica como las que provienen de la corriente epistemológica marxista suponen más un marco de referencia para comprender y analizar la ciudad, que una teoría perfectamente elaborada sobre la nueva realidad que supone el urbanismo contemporáneo. El interés demostrado a partir de los años setenta por ciertos autores, por desarrollar una teoria sobre la ciudad sobre bases marxistas ha tenido dos vías distintas de actuación. Por una parte, la contribución de $\mathrm{M}$. Castells se centra en la necesidad de delimitar, dentro del esquema teórico de $L$. Althusser, los diferentes niveles estructurales que componen la ciudad: el nivel económico, el político-jurídico y el ideológico, así como su reflejo en el espacio. Sin embargo, para Castells, el elemento que posee un carácter más específicamente urbano es el consumo o la reproducción 
de la fuerza de trabajo y sería, por tanto, el de mayor interés a la hora de elaborar una sociologia urbana.

El otro planteamiento de la teoría social marxista tiene lugar en el contexto más general de la economía política, e intenta relacionar, de forma conjunta, los problemas de la producción y el consumo, como dos parcelas inseparables en la reproducción del sistema social. El nexo de unión entre ambos se establece a partir del funcionamiento propio del MPC y la necesidad básica de reproducción ampliada del capital. De esta manera, la reproducción de la fuerza de trabajo no debe ser aislada de la consideración de que el consumo (a nivel individual o colectivo) se convierte en un eslabón más del complicado proceso de acumulación del capital. En ambos planteamientos se intenta introducir el nivel políticojurídico por el papel desempeñado por las clases sociales y el estado en la lucha por el poder en la sociedad y en concreto su traducción en la ciudad, aunque hasta el momento el desarrollo teórico ha sido más bien limitado.

Ambas líneas de investigación deben ser comprendidas dentro de la epistemología marxista que distingue entre la esencia de los fenómenos, de naturaleza oculta, y sus apariencias externas, que producen en la mayoría de los casos un conocimiento ideológico de la realidad social. Esta circunstancia, unida al intento marxista de explicación globalizadora de la sociedad dificulta, aún más, la elaboración de una teoría y su construcción a partir del análisis empírico de los hechos observados. Habiendo sido hasta el momento, ésta última, la forma más habitual de la investigación geográfica clásica, la aplicación de los planteamientos teóricos marxistas resulta difícil de realizar dentro de nuestra disciplina.

Como resumen final, queda señalar la trascendencia que para el desarrollo de la geografía urbana han tenido los principios teóricos, que tanto desde la sociología urbana clásica y la ecología urbana, como desde las perspectivas marxistas o del conflicto social han venido sucediéndose desde principios de siglo. Hemos querido detenernos en el análisis del desarrollo de estas ideas y concepciones desde sus orígenes, en la seguridad de que ello facilitará la comprensión de su introducción y aplicación dentro del campo geográfico. 


\section{BIBLIOGRAFÍA}

Althusser, L., 1969: Para leer el capital. Madrid, Ed. S. XXI.

AsCHER, F., 1975: «Producción del hábitat: contribución al análisis de la producción del hábitat", en Los agentes urbanos y la producción de la vivienda. Barcelona, Univ. Autónoma.

Beltrán, M., 1978: “Acerca de Weber", en Jiménez Blanco, J. y Moya Valgañon, C. Teoría Sociológica Contemporánea. Madrid, Ed. TecnOS, p. 417.

BuRgess, E. W., 1961: "The Growth of a City: an introduction to a research proyect», en PARK, R. E.; Burgess, E. W. y MAC Kenzie, R. P., The City. Chicago, p. 47-62.

Campos VenutTi, G., 1985: «Metrópolis policéntricas y desafío tecnológico». En Metrópolis, territorio y crisis. Revista Alfoz. Madrid.

CAstells, M., 1975: Problemas de investigación en Sociologia Urbana. Madrid, Ed. S. XXI.

-1978: La teoria marxista de las crisis económicas y las transformaciones del capitalismo. Madrid, Ed. S. XXI.

-1979: La cuestión urbana. Madrid, Ed. S. XXI.

-1982: Jornadas: Ciudad y crisis económica. Ponencia. Ayuntamiento de Madrid.

DURKheim, E., 1960: Las formas elementales de la vida religiosa. París, PUF.

-1963: La educación moral. París, PUF.

-1965 a: Las reglas del método sociológico. Buenos Aires, Ed. Schapire.

-1965 b: El suicidio. Buenos Aires, Ed. Schapire. 
EngeLS, F., 1969: The condition of the working class in England. London, St. Albans.

-1977: El problema de la vivienda. Barcelona, Ed. Gustavo Gili.

Giner, S., 1982: Historia del pensamiento social. Barcelona, Ed. Ariel.

HARNECKER, M., 1973: Los conceptos elementales del materialismo histórico. Madrid, Ed. S. XXI.

HARVEY, D., 1976: “Teoría revolucionaria y contrarrevolucionaria en geografía y el problema de la formación del ghetto", en Revista Geocritica, n. ${ }^{\circ}$ 4. Universidad de Barcelona.

-1979: Urbanismo y Desigualdad Social. Madrid, Ed. S. XXI.

-1981: "The urban process under capitalism: a framework for analysis", en Urbanization and urban planning in capitalist society. London, Mehnen Co Ltd.

-1982: The limits to capital. Brasil. Blackwel. Oxford.

HATT, P., 1946: "The concept of natural area», en American Sociological Review, n. ${ }^{\circ} 11$, p. 423-428.

Hawley, A. W., 1950: Human Ecology. N. York.

Herbert, D. T. y Thomas, C. J., 1982: Urban Geography. A first approach. N. York, Ed. Jhon Wriley and Sans.

JiMÉNEZ BlANCO, J., 1978: "Weber, Schutz y Garfinkel sobre racionalidad", en Jiménez Blanco, J. y MOYa Valgañon, C. Teoría Sociológica Contemporánea. Madrid. Ed. Tecnos, p. 366-396-

Lefebvre, H., 1973: El pensamiento marxista y la ciudad. Madrid. Ed. Extemporaneos.

-1976 a: La revolución urbana. Madrid, Ed. Alianza Editorial.

-1976 b: Espacio y Política. Barcelona, Ed. Península.

LOJKINE, J., 1979: El marxismo, el Estado y la cuestión urbana. Madrid. Ed. S. XXI.

Martín Serrano, M., 1978: Métodos actuales de investigación social. Madrid, Ed. Akal.

Marx, K. y Engels, F., 1966: El manifiesto comunista. Moscú, Ed. Progreso.

MaRX, K., 1970: Prefacio a la contribución a la crítica de la economía política. Madrid. Ed. Alberto Corazón. 
-1974: La acumulación originaria de capital. Barcelona, Ed. Grijalbo.

-1978: El Capital. México, Ed. Fondo de Cultura Económica, 3 vols.

PAHL, R., 1970: Patterns of urban life. London, Longman.

-1975: Whose city. London, Penguin.

PARK, R. E., 1936: «Human Ecology», en American Journal Sociology, p. $1-15$.

Pérez Diaz, V., 1980: Introducción a la Sociología. Madrid. Alianza Universidad.

Poulantzas, N., 1972: Poder politico y clases sociales en el estado capitalista. Madrid, Ed. S. XXI.

-1977: Las clases sociales en el capitalismo actual. Madrid, Ed. S. XXI.

REMI, J. y VOYE, L., 1976: La ciudad y la urbanización. Madrid, IEAL.

REX, J. y MOORE, R., 1967: Race, community and Conflict. London, Oxford university Press.

-1968: "The Sociology of a zone of transition", en PAHL, R. Readings in Urban Sociology. London, Pergamon.

RoBson, B. J., 1969: Urban Analysys: A study of city structure. CUP.

SAUNDERS, P., 1981: Social Theory and The urban question. London, Hutchinson.

Simmel, G., 1950: “The metropolis and the mental life», en WOLFF, K. H. The Sociology of George Simmel. N. York, The Free Press.

Sweezy, P., 1970: Teoria del desarrollo capitalista. México, Ed. Fondo de Cultura Económica.

TIMms, D., 1976: El mosaico urbano. Madrid, IEAL.

Topalov, C., 1975: "Un sistema de agentes económicos: la promoción inmobiliaria", en Los agentes urbanos y la producción de la vivienda. Universidad Autónoma de Barcelona, p. 45-95.

Weber, M., 1958: The City. N. York, Free Press.

-1968: Economy and Society. N. York, Beadminster Press.

-1973: Ensayos sobre metodología sociológica. Buenos Aires, Amorrortu. 
La evolución de la problemática urbana en el marco de la teoria social

WILLIANS, P., 1978: «Urban managerialism: toward a political economy of urban allocation". Environment and Planning.

WIRTH, L., 1962: El urbanismo como modo de vida. Buenos Aires, Ed. Paidos. 